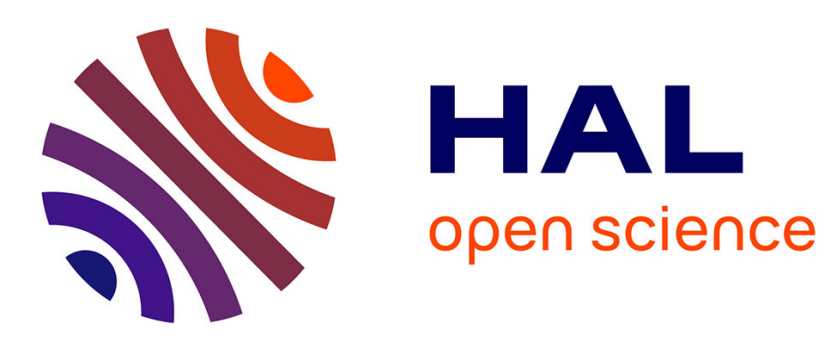

\title{
Analyse de la survie des patients avalanchés en arrêt cardiaque dans les Alpes du Nord
}

Yvonnick Boué

\section{To cite this version:}

Yvonnick Boué. Analyse de la survie des patients avalanchés en arrêt cardiaque dans les Alpes du

Nord. Médecine humaine et pathologie. 2014. dumas-01074130

\section{HAL Id: dumas-01074130 https://dumas.ccsd.cnrs.fr/dumas-01074130}

Submitted on 13 Oct 2014

HAL is a multi-disciplinary open access archive for the deposit and dissemination of scientific research documents, whether they are published or not. The documents may come from teaching and research institutions in France or abroad, or from public or private research centers.
L'archive ouverte pluridisciplinaire HAL, est destinée au dépôt et à la diffusion de documents scientifiques de niveau recherche, publiés ou non, émanant des établissements d'enseignement et de recherche français ou étrangers, des laboratoires publics ou privés. 


\section{Université
Joseph Fourier MEDECINE}

\section{SICD1 \\ Bibliothèques \\ de I'UJF et de Grenoble INP}

\section{AVERTISSEMENT}

Ce document est le fruit d'un long travail approuvé par le jury de soutenance et mis à disposition de l'ensemble de la communauté universitaire élargie.

Il n'a pas été réévalué depuis la date de soutenance.

Il est soumis à la propriété intellectuelle de l'auteur. Ceci implique une obligation de citation et de référencement lors de l'utilisation de ce document.

D'autre part, toute contrefaçon, plagiat, reproduction illicite encourt une poursuite pénale.

Contact au SICD1 de Grenoble : thesebum@ujf-grenoble.fr

\section{LIENS}

Code de la Propriété Intellectuelle. articles L 122. 4

Code de la Propriété Intellectuelle. articles L 335.2- L 335.10

http://www.cfcopies.com/V2/leg/leg_droi.php

http://www.culture.gouv.fr/culture/infos-pratiques/droits/protection.htm 
UNIVERSITE JOSEPH FOURIER

FACULTE DE MEDECINE DE GRENOBLE

Année : 2014

$\mathrm{N}^{\circ}$

\title{
Analyse de la survie des patients avalanchés en arrêt cardiaque dans les Alpes du Nord.
}

\author{
THESE \\ PRESENTEE POUR L'OBTENTION DU DOCTORAT EN MEDECINE \\ DIPLÔME D'ETAT
}

BOUE Yvonnick

Né le 01/04/1984

A LE MANS

THESE SOUTENUE PUBLIQUEMENT A LA FACULTE DE MEDECINE DE GRENOBLE

Le : $25 / 04 / 2014$

DEVANT LE JURY COMPOSE DE

Président du jury : Monsieur le Professeur PAYEN Jean-François

Membres

Monsieur le Professeur ALBALADEJO Pierre

Monsieur le Docteur BOUZAT Pierre, directeur de thèse.

Monsieur le Docteur BRUN Julien

Monsieur le Docteur FRANCONY Gilles

Monsieur le Docteur BRIOT Raphaël 


\section{UFR de Médecine de Grenoble}

DOMAINE DE LA MERCI

38706 LA TRONCHE CEDEX - France

TEL : +33(0)4 76637144

FAX : $+33(0) 476637170$

$\underline{\text { Affaire suivie par Marie-Lise GALINDO sp-medecine-pharmacie@ujf-grenoble.fr }}$

\section{Université MEDECINE}

Doyen de la Faculté : M. le Pr. Jean Paul ROMANET

Année 2013-2014

ENSEIGNANTS A L'UFR DE MEDECINE

\begin{tabular}{|c|c|c|}
\hline CORPS & NOM-PRENOM & Discipline universitaire \\
\hline PU-PH & ALBALADEJO Pierre & Anesthésiologie réanimation \\
\hline MCU-PH & APTEL Florent & Ophtalmologie \\
\hline PU-PH & ARVIEUX-BARTHELEMY Catherine & chirurgie générale \\
\hline PU-PH & BACONNIER Pierre & $\begin{array}{c}\text { Biostatiques, informatique médicale et } \\
\text { technologies de communication }\end{array}$ \\
\hline PU-PH & BAGUET Jean-Philippe & Cardiologie \\
\hline PU-PH & BALOSSO Jacques & Radiothérapie \\
\hline PU-PH & BARRET Luc & Médecine légale et droit de la santé \\
\hline PU-PH & BAUDAIN Philippe & Radiologie et imagerie médicale \\
\hline PU-PH & BEANI Jean-Claude & Dermato-vénéréologie \\
\hline PU-PH & BENHAMOU Pierre Yves & Endocrinologie, diabète et maladies métaboliques \\
\hline PU-PH & BERGER François & Biologie cellulaire \\
\hline PU-PH & BETTEGA Georges & Chirurgie maxillo-faciale, stomatologie \\
\hline MCU-PH & BOISSET Sandrine & Agents infectieux \\
\hline PU-PH & BONAZ Bruno & Gastro-entérologie, hépatologie, addictologie \\
\hline MCU-PH & BONNETERRE Vincent & Médecine et santé au travail \\
\hline PU-PH & BOSSON Jean-Luc & $\begin{array}{c}\text { Biostatiques, informatique médicale et } \\
\text { technologies de communication }\end{array}$ \\
\hline MCU-PH & BOTTARI Serge & Biologie cellulaire \\
\hline PU-PH & BOUGEROL Thierry & Psychiatrie d'adultes \\
\hline PU-PH & BOUILLET Laurence & Médecine interne \\
\hline MCU-PH & BOUZAT Pierre & Réanimation \\
\hline PU-PH & BRAMBILLA CHRISTIAN & Pneumologie \\
\hline PU-PH & BRAMBILLA Elisabeth & Anatomie et cytologie pathologiques \\
\hline MCU-PH & BRENIER-PINCHART Marie Pierre & Parasitologie et mycologie \\
\hline PU-PH & BRICAULT Ivan & Radiologie et imagerie médicale \\
\hline PU-PH & BRICHON Pierre-Yves & Chirurgie thoracique et cardio- vasculaire \\
\hline MCU-PH & BRIOT Raphaël & Thérapeutique, médecine d'urgence \\
\hline PU-PH & CAHN Jean-Yves & Hématologie \\
\hline MCU-PH & CALLANAN-WILSON Mary & Hématologie, transfusion \\
\hline PU-PH & CARPENTIER Françoise & Thérapeutique, médecine d'urgence \\
\hline
\end{tabular}




\begin{tabular}{|c|c|c|}
\hline PU-PH & CARPENTIER Patrick & Chirurgie vasculaire, médecine vasculaire \\
\hline PU-PH & CESBRON Jean-Yves & Immunologie \\
\hline PU-PH & CHABARDES Stephan & Neurochirurgie \\
\hline PU-PH & CHABRE Olivier & Endocrinologie, diabète et maladies métaboliques \\
\hline PU-PH & CHAFFANJON Philippe & Anatomie \\
\hline PU-PH & CHAVANON Olivier & Chirurgie thoracique et cardio- vasculaire \\
\hline PU-PH & CHIQUET Christophe & Ophtalmologie \\
\hline PU-PH & CHIROSSEL Jean-Paul & Anatomie \\
\hline PU-PH & CINQUIN Philippe & $\begin{array}{c}\text { Biostatiques, informatique médicale et } \\
\text { technologies de communication }\end{array}$ \\
\hline PU-PH & COHEN Olivier & $\begin{array}{c}\text { Biostatiques, informatique médicale et } \\
\text { technologies de communication }\end{array}$ \\
\hline PU-PH & COUTURIER Pascal & Gériatrie et biologie du vieillissement \\
\hline PU-PH & CRACOWSKI Jean-Luc & $\begin{array}{c}\text { Pharmacologie fondamentale, pharmacologie } \\
\text { clinique }\end{array}$ \\
\hline PU-PH & DE GAUDEMARIS Régis & Médecine et santé au travail \\
\hline PU-PH & DEBILLON Thierry & Pédiatrie \\
\hline MCU-PH & DECAENS Thomas & Gastro-entérologie, Hépatologie \\
\hline PU-PH & DEMATTEIS Maurice & Addictologie \\
\hline PU-PH & DEMONGEOT Jacques & $\begin{array}{c}\text { Biostatiques, informatique médicale et } \\
\text { technologies de communication }\end{array}$ \\
\hline MCU-PH & DERANSART Colin & Physiologie \\
\hline PU-PH & DESCOTES Jean-Luc & Urologie \\
\hline MCU-PH & DETANTE Olivier & Neurologie \\
\hline MCU-PH & DIETERICH Klaus & Génétique et procréation \\
\hline MCU-PH & DUMESTRE-PERARD Chantal & Immunologie \\
\hline PU-PH & ESTEVE François & Biophysique et médecine nucléaire \\
\hline MCU-PH & EYSSERIC Hélène & Médecine légale et droit de la santé \\
\hline PU-PH & FAGRET Daniel & Biophysique et médecine nucléaire \\
\hline PU-PH & FAUCHERON Jean-Luc & chirurgie générale \\
\hline MCU-PH & FAURE Julien & Biochimie et biologie moléculaire \\
\hline PU-PH & FERRETTI Gilbert & Radiologie et imagerie médicale \\
\hline PU-PH & FEUERSTEIN Claude & Physiologie \\
\hline PU-PH & FONTAINE Éric & Nutrition \\
\hline PU-PH & FRANCOIS Patrice & $\begin{array}{c}\text { Epidémiologie, économie de la santé et } \\
\text { prévention }\end{array}$ \\
\hline PU-PH & GARBAN Frédéric & Hématologie, transfusion \\
\hline PU-PH & GAUDIN Philippe & Rhumatologie \\
\hline PU-PH & GAVAZZI Gaétan & Gériatrie et biologie du vieillissement \\
\hline PU-PH & GAY Emmanuel & Neurochirurgie \\
\hline MCU-PH & GILLOIS Pierre & $\begin{array}{l}\text { Biostatiques, informatique médicale et } \\
\text { technologies de communication }\end{array}$ \\
\hline PU-PH & GODFRAIND Catherine & $\begin{array}{c}\text { Anatomie et cytologie pathologiques } \\
\text { (type clinique) }\end{array}$ \\
\hline MCU-PH & GRAND Sylvie & Radiologie et imagerie médicale \\
\hline PU-PH & GRIFFET Jacques & Chirurgie infantile \\
\hline MCU-PH & GUZUN Rita & $\begin{array}{c}\text { Endocrinologie, diabétologie, nutrition, } \\
\text { éducation thérapeutique }\end{array}$ \\
\hline
\end{tabular}




\begin{tabular}{|c|c|c|}
\hline PU-PH & HALIMI Serge & Nutrition \\
\hline PU-PH & HENNEBICQ Sylviane & Génétique et procréation \\
\hline PU-PH & HOFFMANN Pascale & Gynécologie obstétrique \\
\hline PU-PH & HOMMEL Marc & Neurologie \\
\hline PU-PH & JOUK Pierre-Simon & Génétique \\
\hline PU-PH & JUVIN Robert & Rhumatologie \\
\hline PU-PH & KAHANE Philippe & Physiologie \\
\hline PU-PH & KRACK Paul & Neurologie \\
\hline PU-PH & KRAINIK Alexandre & Radiologie et imagerie médicale \\
\hline PU-PH & LABARERE José & Département de veille sanitaire \\
\hline PU-PH & LANTUEJOUL Sylvie & Anatomie et cytologie pathologiques \\
\hline MCU-PH & LAPORTE François & Biochimie et biologie moléculaire \\
\hline MCU-PH & LARDY Bernard & Biochimie et biologie moléculaire \\
\hline MCU-PH & LARRAT Sylvie & Bactériologie, virologie \\
\hline MCU-PH & LAUNOIS-ROLLINAT Sandrine & Physiologie \\
\hline PU-PH & LECCIA Marie-Thérèse & Dermato-vénéréologie \\
\hline PU-PH & LEROUX Dominique & Génétique \\
\hline PU-PH & LEROY Vincent & Gastro-entérologie, hépatologie, addictologie \\
\hline PU-PH & LETOUBLON Christian & chirurgie générale \\
\hline PU-PH & LEVY Patrick & Physiologie \\
\hline MCU-PH & LONG Jean-Alexandre & Urologie \\
\hline PU-PH & MACHECOURT Jacques & Cardiologie \\
\hline PU-PH & MAGNE Jean-Luc & Chirurgie vasculaire \\
\hline MCU-PH & MAIGNAN Maxime & Thérapeutique, médecine d'urgence \\
\hline PU-PH & MAITRE Anne & Médecine et santé au travail \\
\hline MCU-PH & MALLARET Marie-Reine & $\begin{array}{c}\begin{array}{c}\text { Epidémiologie, économie de la santé et } \\
\text { prévention }\end{array} \\
\end{array}$ \\
\hline MCU-PH & MARLU Raphaël & Hématologie, transfusion \\
\hline MCU-PH & MAUBON Danièle & Parasitologie et mycologie \\
\hline PU-PH & MAURIN Max & Bactériologie - virologie \\
\hline MCU-PH & MCLEER Anne & Cytologie et histologie \\
\hline PU-PH & MERLOZ Philippe & Chirurgie orthopédique et traumatologie \\
\hline PU-PH & MORAND Patrice & Bactériologie - virologie \\
\hline PU-PH & MOREAU-GAUDRY Alexandre & $\begin{array}{c}\text { Biostatiques, informatique médicale et } \\
\text { technologies de communication }\end{array}$ \\
\hline PU-PH & MORO Elena & Neurologie \\
\hline PU-PH & MORO-SIBILOT Denis & Pneumologie \\
\hline MCU-PH & MOUCHET Patrick & Physiologie \\
\hline PU-PH & MOUSSEAU Mireille & Cancérologie \\
\hline PU-PH & MOUTET François & $\begin{array}{c}\text { Chirurgie plastique, reconstructrice et } \\
\text { esthétique, brûlogie }\end{array}$ \\
\hline MCU-PH & PACLET Marie-Hélène & Biochimie et biologie moléculaire \\
\hline PU-PH & PALOMBI Olivier & Anatomie \\
\hline PU-PH & PARK Sophie & Hémato - transfusion \\
\hline PU-PH & PASSAGGIA Jean-Guy & Anatomie \\
\hline
\end{tabular}




\begin{tabular}{|c|c|c|}
\hline PU-PH & PAYEN DE LA GARANDERIE Jean-François & Anesthésiologie réanimation \\
\hline MCU-PH & PAYSANT François & Médecine légale et droit de la santé \\
\hline MCU-PH & PELLETIER Laurent & Biologie cellulaire \\
\hline PU-PH & PELLOUX Hervé & Parasitologie et mycologie \\
\hline PU-PH & PEPIN Jean-Louis & Physiologie \\
\hline PU-PH & PERENNOU Dominique & Médecine physique et de réadaptation \\
\hline PU-PH & PERNOD Gilles & Médecine vasculaire \\
\hline PU-PH & PIOLAT Christian & Chirurgie infantile \\
\hline PU-PH & PISON Christophe & Pneumologie \\
\hline PU-PH & PLANTAZ Dominique & Pédiatrie \\
\hline PU-PH & POLACK Benoît & Hématologie \\
\hline PU-PH & POLOSAN Mircea & Psychiatrie d'adultes \\
\hline PU-PH & PONS Jean-Claude & Gynécologie obstétrique \\
\hline PU-PH & RAMBEAUD Jacques & Urologie \\
\hline MCU-PH & RAY Pierre & Génétique \\
\hline PU-PH & REYT Émile & Oto-rhino-laryngologie \\
\hline MCU-PH & RIALLE Vincent & $\begin{array}{c}\text { Biostatiques, informatique médicale et } \\
\text { technologies de communication }\end{array}$ \\
\hline PU-PH & RIGHINI Christian & Oto-rhino-laryngologie \\
\hline PU-PH & ROMANET J. Paul & Ophtalmologie \\
\hline MCU-PH & ROUSTIT Matthieu & $\begin{array}{c}\text { Pharmacologie fondamentale, pharmaco } \\
\text { clinique, addictologie }\end{array}$ \\
\hline MCU-PH & ROUX-BUISSON Nathalie & Biochimie, toxicologie et pharmacologie \\
\hline PU-PH & SARAGAGLIA Dominique & Chirurgie orthopédique et traumatologie \\
\hline MCU-PH & SATRE Véronique & Génétique \\
\hline PU-PH & SCHMERBER Sébastien & Oto-rhino-laryngologie \\
\hline PU-PH & SCHWEBEL-CANALI Carole & Réanimation médicale \\
\hline PU-PH & SCOLAN Virginie & Médecine légale et droit de la santé \\
\hline MCU-PH & SEIGNEURIN Arnaud & $\begin{array}{c}\text { Epidémiologie, économie de la santé et } \\
\text { prévention }\end{array}$ \\
\hline PU-PH & SERGENT Fabrice & Gynécologie obstétrique \\
\hline PU-PH & SESSA Carmine & Chirurgie vasculaire \\
\hline PU-PH & STAHL Jean-Paul & Maladies infectieuses, maladies tropicales \\
\hline PU-PH & STANKE Françoise & Pharmacologie fondamentale \\
\hline MCU-PH & STASIA Marie-José & Biochimie et biologie moléculaire \\
\hline PU-PH & TAMISIER Renaud & Physiologie \\
\hline PU-PH & TONETTI Jérôme & Chirurgie orthopédique et traumatologie \\
\hline PU-PH & TOUSSAINT Bertrand & Biochimie et biologie moléculaire \\
\hline PU-PH & VANZETTO Gérald & Cardiologie \\
\hline PU & VILLA Alessandro & Neurosciences \\
\hline PU-PH & VUILLEZ Jean-Philippe & Biophysique et médecine nucléaire \\
\hline PU-PH & WEIL Georges & $\begin{array}{c}\text { Epidémiologie, économie de la santé et } \\
\text { prévention }\end{array}$ \\
\hline PU-PH & ZAOUI Philippe & Néphrologie \\
\hline PU-PH & ZARSKI Jean-Pierre & Gastro-entérologie, hépatologie, addictologie \\
\hline
\end{tabular}




\section{Remerciements}

Je remercie les membres du jury d'avoir accepté de juger mon travail :

Le président du jury, le Professeur PAYEN Jean-François, je vous remercie pour l'intérêt que vous avez su me porter, pour votre proximité, pour l'enseignement que j'ai pu recevoir de tous les acteurs du Pôle Anesthésie-Réanimation depuis bientôt 6 ans.

Le Professeur ALBALADEJO Pierre, je vous remercie de faire partie de ce jury de thèse en tant qu'anesthésiste-réanimateur exerçant en chirurgie cardiaque et réanimation cardiovasculaire puisque pour la moitié l'effectif de cette étude a bénéficié d'une assistance circulatoire. L'expertise des circulations extracorporelles et de l'ischémie-reperfusion s'avère donc nécessaire.

Le directeur de thèse, le Docteur BOUZAT, Pierre merci de m'avoir encadré aussi efficacement pour ce travail. Ton dynamisme et ta réactivité ont permis d'aboutir rapidement à cet article. Je suis très honoré par les projets universitaires proposés à l'aube du clinicat. C'est avec une très grande motivation et satisfaction que j'intègre votre équipe du PU-DCA en mai prochain.

Le Docteur FRANCONY, Gilles, merci d'avoir continué à attiser ma passion pour notre métier. Tu fais partie de ces rencontres décisives dans une vie, de ces déclics qui donnent tout le sens à notre métier. J'admire cette façon que tu as d'exercer l'anesthésieréanimation alliant les qualités du médecin par ton savoir, de l'humaniste par ton savoir-être et du technicien par ton savoir-faire.

Le Docteur BRUN, Julien, merci d'avoir montré que le parcours de l'anesthésisteréanimateur pouvait être d'une extrême polyvalence. Cette qualité qui fait l'intérêt de notre métier : déchoqueur-réanimateur la semaine, médecin du secours en montagne le week-end, SMURISTE ou bien réanimateur pédiatrique le vendredi soir. Merci par tes précédents d'avoir inspiré cette démarche, satisfaction non dénuée d'investissements.

Le Docteur BRIOT, Raphäl, merci en tant que médecin du pré-hospitalier et du secours en montagne d'être membre du jury. Merci également de me faire confiance depuis 4 ans sur les gardes au SAMU 38 et depuis 3 ans sur les permanences du secours en montagne. 
Je remercie ma famille qui, à l'origine de cet aboutissement, a su bâtir le socle de ma vie et m'aider chaque fois à ajouter une pierre à l'édifice,

A mes grands parents, à tous les instants dans mon corps et dans ma tête, merci de m'avoir donné votre amour, votre énergie et les meilleures chances de réussite. A mes grands pères Jean et Joseph qui me donnent la détermination. A ma grand-mère Simone qui nous manque beaucoup trop, je lui dédie cette soutenance. A ma grand-mère Chantal, pour son dynamisme, sa vivacité d'esprit, son humour, sa philosophie.

A mes parents, Florence et Jean-Yves, qui m’ont permis de hisser les plus belles voiles et de suivre le meilleur cap.

A ma sœur, Anaïs, Nana, pour notre complicité, pour ta joie de vivre, ton charisme, le bonheur des moments partagés avec toi. A François.

A Jean-Pierre, mon troisième grand-père pour m'avoir considéré comme son petit-fils.

A André et Sandrine.

A Patricia, Cyril et Eric.

A Jeanine, Nathalie, Denis, Yannick, Sophia, Fabien, Julien, Alexis.

A mes arrières grands parents.

A la famille Boué, Martel, Raimondo, Fascio au sens large.

Aux amis de la famille Boué : Hubert, Corinne, Dominique Yungdrung Tenzin Troulay, Françoise, Christian, Annie, Alain, Marie. 
Je remercie mes amis,

David, tant de fois où nous avons parcouru le chemin du collège ensemble...

\section{Les malouins :}

Erwan, j'ai hâte de renaviguer avec toi à la voile ou de partager de nouveau une bonne session de planche.

Nico, $\mathrm{Mr}$ Croc, à celui qui m'a montré comment le bonheur et la joie de vivre pouvaient être simple comme un sourire (ultrabright!). Grâce à toi, les maths et la physique n'ont plus d'obscurité pour moi, enfin surtout les vagues et les soirées de Tarifa et de Guincho!

Jean-Marie, toi qui m'as mis le pied à l'étrier des études médicales, toi qui m'as surmotivé pour faire one shot au concours.

\section{Les Rennais :}

Olivier, tant de moments à rire avec toi, à partager les galères avec toujours un dénouement heureux. Merci pour ta joie de vivre, ta constance dans les relations humaines, ta générosité et toutes ces choses pour lesquelles nous sommes liés d'amitiés. A Christelle et votre fille.

Manu, pour les instants passés à naviguer, philosopher, préparer un concours. Pour tous ces moments d'amitiés si précieux. A nos prochaines navigations à l'image du tour de Corse et tes qualités de numéro 1. A Louisa.

Anne-Claire, Zippette, déjà plus de 10 ans de moments partagés, à échanger, à philosopher sur le pont d'un voilier, dans un hôpital Guinéen ou un village Péruvien.

Anne-Laure, pour les rocks à $3600 \mathrm{~m}$ d'altitude et la Chicha du Colca. A $J B$ pour le bon temps partagé en Corse.

Camille, Pouette, en souvenir de nos virées bretonnes en planche, kite ou voile. $A$ Anne et la petite Salomé.

Benjamin, le rouquin, pour le trop peu de moments partagés ensemble. A Elodie et la petite Youna.

Quiterie, pour les moments de complicité passés en mer, à terre ou dans le port de Guernesey!

Jean-Briac, le guitariste, Dylan n'est pas mort. A Anne-Claire et votre petite Eléna.

\section{Les Grenoblois :}

Julien, à nos moments partagés sur une pente raide ou encordés, à notre sens du timing, à Théodore et Siméon, à notre amitié qui a été plus forte que notre galère de grimpe.

Thibaut, mon Totob, la révélation Grenobloise. N'oublie pas nos projets de circumnavigation! J'ai hâte de te revoir sur Grenoble. A Justine qui reste ta première femme !

Gautier, mon bichon, à nos escapades montagnardes et marines à tes heures perdues. Et surtout n'oublie pas les chaussettes de ta grand-mère ! 
Mathieu, la force tranquille, un raz de marée de gentillesse, toujours prêt pour aller faire $40 \mathrm{~km}$ de trail à l'UT4M. A Sophie.

Elophe, pour ton approche de la montagne : « la sécu, le plaisir et les copains avant tout »

Jim, pour ton petit grain de folie en mode breton l'explorateur et vive le pâté Henaff dans le 5.2. A tes petites femmes Manu et Anouk.

David, Davidou à toutes nos escapades à ski, à la voile ou en alpi, c'est que du bonheur

Nico, Coquinou, à ta fougue sur tes pelles à tarte et surtout jamais moins de $10 \mathrm{~cm} \mathrm{au}$ patin et $3000 \mathrm{~m}$ dans les gambettes

Arnold, Marie et leurs enfants, pour leur joie de vivre à toute épreuve.

Juju Lavolaine, en souvenir de notre bivouac au glacier blanc et de toutes les suivantes. Claire-Marie, pour sa « punchy attitude»

Adrien, " beau gosse ", petit animal du désert toujours prêt pour un petit baijo et une blague belge ou portugaise. A la géniale Dorothée.

Laure, Laurette sur un air d'accordéon ou de flûte, bercé par la houle.

Raphaëlle, Raph' toujours prête pour faire $80 \mathrm{~km}$ à vélo ! Martin, Carré pour ton sens de l'anticipation, ton humour indémodable.

Charline, amiral Chouillon pour ton sens de la navigation et ta gestion du mal de mer. A Numa pour ton feeling à la barre d'un voilier et aux commandes d'un scooter.

Xavier, Kaiser Chauchette, pour ta fougue, ton humour et ton entrain. A Nancy et l'enfant que tu portes dans ton ventre.

Charlotte, la danseuse, toujours prête à danser un rock. Romain pour ton goput du déguisement. Ninon, déjà prête pour la crèche!

Gilles, la rencontre chambérienne, à nos poilades autour d'un petit suisse, en chaussures d'approche. A notre virée à l'aigle pour un vol inoubliable. A ton sens de la déconne et de la philosophie.

Olivier Carle, à nos courbes dans la fraiche du Beaufortin, pour tes petits plats à bord quelques soient les conditions, et ton sens de la fête à terre.

Olivier Jeauneau, en espérant pouvoir repartir à la voile en ensemble, un cassoulet bien chaud entre les cuisses!

Sylvain, l'infâme, en souvenir de nos vols et en vue des prochains.

Clotilde, pour ta pêche et ton franc parlé. A Loulou.

Séb Thomas, pour ta gentillesse, tes bons conseils et nos escapades à ski. A AnneLaure, Paul et Justine.

Lara, pour ton sens du groupe et l'organisation, ta fondue, ton avion pour le Brésil.

A Philippe le BG et Marie pour son côté PJ (Pièce Jointe).

Mathilde, la spéléo de choc, Jorge l'espagnol alpiniste notre ostéo préféré et leur magnifique Paloma. 
Je remercie mes collègues, médecins, internes, infirmiers anesthésistes, infirmiers, ambulanciers, aides soignants, brancardiers, kinésithérapeutes, secouristes, pilotes, mécaniciens, puéricultrices, auxiliaires puéricultrices, sages femmes, secrétaires (mention spéciale à Joce PAULUS, Corinne MARCHAND, Sandrine DAMIANI et Françoise FAURE).

Ma promotion d'internes en particulier Amélie, Thomas, Luc. La promo des drôles de dames en particulier Perrine, Marion, Pierre-Henry. La promo des vieux Bardoune, Christine, Lulu, Amélie. Et les promotions des plus jeunes.

L'équipe de neuro-réanimation en particulier Marco VINCLAIR l'aventurier pour toute ton inspiration au delà des frontières du CHU, Bashar OUMMAHAN le traileur pour le plaisir à travailler avec toi, François pour ton sens du service public.

L'équipe du déchocage, Karine BERGER et Françoise BOUILLET pour votre «Zen attitude » en toutes circonstances. C'est un aboutissement de rejoindre votre équipe en mai.

L'équipe de réanimation polyvalente chirurgicale pour m'avoir formé à mon arrivée au CHU puis fait confiance pendant plus de 2 ans sur les gardes. C'est avec satisfaction et motivation que je vous rejoins en novembre 2015.

L'équipe du SAMU 38, tout particulièrement JP TORRES pour son partage d'expérience sur l'avalanché, Elisabeth RANCUREL, FX THEVENIN, Maxime MAIGNAN, FX KOCH, Christophe ESCALLIER.

L'équipe de l'Unité de Montagne de Huez (UMH), avec une mention spéciale pour France ROCOURT qui m'a permis de m'accrocher au treuil il y a 3 ans, Marc BLANCHER pour m'avoir permis de m'exprimer dans l'amphithéâtre de l'ENSA et de m'investir dans le secours en montagne, Isa FAVIER et Katell BERTHELOT pour m'avoir rapidement considéré comme un confrère. Les médecins de l'ANMSM en particulier Pierre VISINTINI.

Le PGHM, la CRS Alpes, et la base hélicoptère de la sécurité civile de Grenoble, pour les moments passés à Huez ou au Versoud. Pour cet échange entre professionnels de la montagne, du pilotage, du treuillage et de la médecine.

L'équipe de réanimation du Dr THOURET, CH de Chambéry, pour avoir partagé avec vous le début de l'aventure ECMO, pour m'avoir laissé les clés de la maison sur les gardes, pour votre formation et votre bonne humeur au travail.

L'équipe de réanimation pédiatrique, en particulier le $\operatorname{Dr}$ WROBLEWSKI, Isabelle, merci d'avoir développé le côté pédiatre caché en moi ! Merci pour la formation que j'ai pu recevoir et les responsabilités que vous m'avez déléguées sur les gardes.

L'équipe d'anesthésie pédiatrique, tout particulièrement, les Drs CARLE et CARTAL, Olivier, Marielle merci pour votre formation et l'intérêt que vous me portez. J'espère que je pourrais continuer à travailler avec vous.

La réanimation Cardiocirculatoire pour la formation hémodynamique et pour avoir confirmer mon goût pour l'ECMO.

L'équipe du Dr VENET d'anesthésie et de l'USC de Voiron, pour l'accueil que j'ai reçu et le plaisir à travailler avec vous.

$L$ 'équipe du Dr DUBOIS de la clinique mutualiste et leur dream team.

La réanimation médicale du Pr LE TULZO, CHU de Rennes, en particulier le Dr $L A V O U E$, Sylvain qui a fait naitre cette passion de la réanimation.

Au Dr VIGHETTI Arnaud pour son humanité en toute circonstance. 
A ma petite femme, Fanny pour avoir changé ma vie, pour l'amour que tu me portes chaque seconde qui s'écoule, pour l'amour que j'éprouve à chacun de tes sourires, pour tous les moments passés, présents et à venir.

«Ce n'est pas parce que les choses sont difficiles que nous n'osons pas, c'est parce que nous n'osons pas qu'elles sont difficiles.»

Sénèque 
Sommaire

$\begin{array}{ll}\text { Remerciements. } & \text { p } 6\end{array}$

Abstract en français. $\quad$ p 13

$\begin{array}{ll}\text { Abstract en anglais. } & \text { p } 14\end{array}$

$\begin{array}{ll}\text { I. Introduction. } & \mathrm{p} 15\end{array}$

II. Contexte scientifique : rappels bibliographiques. p 16

A. Données épidémiologiques. p 16

$\begin{array}{ll}\text { B. Durée d'ensevelissement. } & \text { p } 17\end{array}$

C. Relation kaliémie-anoxie p 18

$\begin{array}{ll}\text { D. Température corporelle. } & \text { p } 18\end{array}$

$\begin{array}{ll}\text { E. Rythme cardiaque. } & \text { p } 19\end{array}$

F. Durée de réanimation. $\quad$ p 19

G. Voies aériennes, poche à air, Triple H Syndrome. p 20

H. Profondeur d'ensevelissement. p 20

I. Neuroprotection et hypothermie. $\quad$ p 21

J. Rescue Collapse et After Drop. p 23

K. Les thérapeutiques de réchauffement. p 24

L. Détecteur de victimes d'avalanche (DVA) et Airbag. p 24

III. Matériel et méthodes. $\quad$ p 25

IV. Résultats. p p 28

$\begin{array}{lr}\text { V. Discussion. } & \text { p } 36\end{array}$

$\begin{array}{ll}\text { VI. Conclusion. } & \text { p } 39\end{array}$

$\begin{array}{ll}\text { VII. Bibliographies. } & \mathrm{p} 42\end{array}$

$\begin{array}{ll}\text { VIII. Annexes. } & \text { p } 48\end{array}$

IX. Article soumis à Resuscitation. p 54 


\section{Résumé}

Introduction: Trois mécanismes sont impliqués au cours des arrêts cardiorespiratoires (ACR) suite à un ensevelissement complet par avalanche : l'anoxie, le traumatisme ou l'hypothermie. La distinction de ces 3 étiologies est difficile chez ces patients alors que seul l'ACR par hypothermie profonde nécessite une réanimation prolongée. L'objectif de notre étude a donc été d'évaluer les facteurs pré-hospitaliers et hospitaliers associés à la survie chez les patients avalanchés en ACR.

Matériel et méthodes: Nous avons étudié rétrospectivement de 1994 à 2013 tous les avalanchés en ACR admis au déchocage suite à un ensevelissement par avalanche. Le registre du Réseau de Traumatologie Nord Alpin des Urgences a permis le recueil des données. Le triage pré-hospitalier suivait les recommandations internationales. A l'admission hospitalière, les patients transportés sous massage cardiaque étaient récusés à l'assistance circulatoire en cas de traumatisme sévère diagnostiqué au bilan initial, d'une kaliémie supérieure à 10 $\mathrm{mmol} / \mathrm{L}$ ou d'une température centrale supérieure à $32^{\circ} \mathrm{C}$. Les facteurs associés à la survie hospitalière étaient déterminés par analyse univariée (Test non paramétrique de MannWithney). L'évolution neurologique était évaluée par le score Cerebral Performance Category $(\mathrm{CPC})$ à 3 mois.

Résultats : 48 patients ont été inclus. A l'admission hospitalière, 11 patients ont été récusés à l'assistance circulatoire $\mathrm{du}$ fait d'une hyperkaliémie ( $\mathrm{n}=8$ patients), d'une température supérieure à $32^{\circ} \mathrm{C}(\mathrm{n}=2$ patients) ou d'un traumatisme thoracique ( $\mathrm{n}=1$ patient). 21 patients ont bénéficié d'une assistance circulatoire pour ACR réfractaire $(n=19)$ ou pour une instabilité hémodynamique persistante $(\mathrm{n}=2) .16$ patients présentaient une reprise d'activité circulatoire spontanée à l'admission. Les patients non-survivants ( $\mathrm{n}=29$ patients) présentaient une kaliémie plus élevée (5.6 mmol/L [4.2-4.8 mmol/L] vs $3.2 \mathrm{mmol} / \mathrm{L}$ [2.7-4 mmol/L], P=0.001), un TCA ratio plus long (3.3 [1.9-3.7] vs 1.3 [0.9-1.9], $\mathrm{P}=0.01)$, un TP plus bas (30\% [19$51 \%$ ] vs $64 \%$ [54-83\%], $\mathrm{P}=0.01)$ et un fibrinogène plus bas $(1.1 \mathrm{~g} / \mathrm{L}[0.6-1.7 \mathrm{~g} / \mathrm{L}]$ vs $1.7 \mathrm{~g} / \mathrm{L}$ [1.6-2.3 g/L], $\mathrm{P}=0.04)$ par rapport aux patients survivants $(\mathrm{n}=8$ patients). Parmi les patients survivants, 3 patients présentaient un score CPC de 1, 1 patients un score CPC de 3 et 4 patients un score CPC de 4. Parmi les 3 patients sans séquelles neurologiques (CPC1), tous ont présenté des signes de vie ou une poche à air avant l'extraction.

Discussion : En pré-hospitalier, la présence d'une poche à air a été associée à la survie ainsi que la présence de signes de vie avant l'ACR. En association avec l'hyperkaliémie, les troubles de coagulation, grâce aux outils de biologie délocalisée, pourraient également intégrer l'algorithme de triage pour la mise en place d'une assistance circulatoire en cas d'ACR réfractaire.

Mots Clés : avalanche, arrêt cardiaque, hypothermie, ensevelissement. 


\section{Survival after avalanche-induced cardiac arrest}

\section{Abstract}

Aim: Defining criteria to prolong resuscitation after cardiac arrest (CA) induced by avalanche is essential due to the role of associated profound hypothermia. We sought parameters associated with survival in a cohort of victims from complete avalanche burial.

Methods: Retrospective observational study from 1994 to 2013 in the Northern French Alps with on-scene CA patients after avalanche burial. Criteria associated with survival at the intensive care unit (ICU) discharge were collected on the scene and at the admission to Level1 trauma center. Neurological outcome was assessed at 3 months using cerebral performance category.

Results: Forty-eight patients were studied. They were buried for a median 43 min (25-76 min; $25-75^{\text {th }}$ percentiles) and had a pre-hospital body core temperature of $28.0^{\circ} \mathrm{C}(26.0-30.7)$. Eighteen patients had pre-hospital return of spontaneous circulation and 30 had refractory CA. Twenty-one patients had extracorporeal life support for rewarming. Eight patients survived at ICU discharge and 3 patients had favorable neurological outcome at 3 months. Pre-hospital parameters associated with survival were the presence of air pocket and a rescue collapse. On admission, non-survivors had higher serum potassium concentration than survivors: $5.6 \mathrm{mmol} / \mathrm{L}(4.2-8.0)$ versus $3.2 \mathrm{mmol} / \mathrm{L}(2.7-4.0)$, respectively $(\mathrm{P}<0.01)$. They also had more disturbances in prothrombin and activated partial thromboplastin ratios.

Conclusions: Our findings indicate that survival after avalanche burial and on-scene CA is rarely associated with favourable neurological outcome. Assessment of blood coagulation on admission of these patients would deserve further confirmation.

Key words: cardiac arrest, avalanche, burial, hypothermia 
I. Introduction.

Les avalanches sont responsables de 150 décès par an en Amérique du Nord et en Europe $^{1}$. Le taux de mortalité dépasse $70 \%$ en cas d'ensevelissement complet ${ }^{2}$. On distingue trois causes principales d'Arrêt Cardio-Respiratoire (ACR) après un ensevelissement complet : l'anoxie, le traumatisme ou/et l'hypothermie profonde ${ }^{1,3}$. L'anoxie, en plus d'être la principale cause de décès, est d'évolution neurologique défavorable ${ }^{1,3-5}$. En effet, en fonction des séries, l'anoxie est impliquée dans 75 à $92 \%$ des cas d'ACR par ensevelissement ${ }^{3-5}$. Les traumatismes sévères représentent également une cause fréquente d'ACR au cours des ensevelissements par avalanche $e^{1,3-5}$ et sont associés à une forte mortalité au moins aussi élevée que les ACR traumatiques de la voie publique ${ }^{6}$. A contrario, les ACR par hypothermie sévère sont moins fréquents ${ }^{1,3}$. Cependant, du fait de la neuroprotection induite par l'hypothermie accidentelle, ils représentent un contexte physiopathologique favorable en terme d'évolution neurologique malgré des durées d'ensevelissement extrêmement prolongées $^{1,3,7,8}$.

Dans le contexte clinique, la mise en évidence de la cause de l'ACR chez l'avalanché est délicate voir impossible. En effet, ces différents mécanismes d'ACR peuvent être associés et en cas d'hypothermie la décision de transport sous massage cardiaque externe (MCE) vers le déchocage d'un centre hospitalier habilité à implanter une assistance circulatoire (ExtraCorporal Life Support : ECLS) peut être retenue ${ }^{1}$. Les recommandations internationales proposent d'interrompre la réanimation en préhospitalier en cas d'asystolie associée à des lésions létales, un corps gelé sur lequel des compressions thoraciques seraient inefficaces, une obstruction des voies aériennes supérieures (VAS) et un ensevelissement de plus de 35 minutes $^{1}$ (Figure 1). Après transport en milieu hospitalier, une kaliémie inférieure à 12 $\mathrm{mmol} / \mathrm{L}$ est retenue pour poser l'indication d'ECLS à condition que la température corporelle soit confirmée inférieure à $32^{\circ} \mathrm{C}$ à l'admission ${ }^{1}$. En dehors des lésions létales évidentes, les critères de triage pré-hospitalier sont souvent non contributifs. En effet, la mise en évidence d'une poche à air, la liberté des $\operatorname{VAS}^{9}$, la fiabilité de la durée d'ensevelissement sont souvent difficiles à déterminer. Par ailleurs, la valeur de la kaliémie est rarement supérieure à 12 $\mathrm{mmol} / \mathrm{L}^{9-12}$. Il y a donc une véritable nécessité de mettre en évidence d'autres marqueurs pronostiques de survie afin d'améliorer le triage de ces patients. Le but de ce travail rétrospectif sur 20 ans est de préciser et mettre en évidence des paramètres associés à la survie et au devenir neurologique en cas d'ACR afin de sélectionner pertinemment les patients relevant d'une réanimation prolongée. 


\section{Contexte scientifique.}

\section{A. Données épidémiologiques.}

En Amérique du Nord et en Europe, on estime à 150/an le nombre de décès par avalanche $^{2}$. Dans les pays alpins européens (Autriche, France, Allemagne, Italie, Slovénie et Suisse) la mortalité est stable ${ }^{13}$. En revanche, au Canada et aux Etats-Unis, on note une augmentation nette de mortalité ${ }^{13}$. En cas d'ensevelissement complet, la mortalité globale dépasse $70 \%$ alors qu'elle est estimée à $4.2 \%$ lors d'un ensevelissement partiel ${ }^{2,13}$. Trois mécanismes sont impliqués dans la survenue d'un ACR au cours d'une avalanche : l'anoxie, le traumatisme et/ou l'hypothermie ${ }^{3,13}$. L'anoxie représente la principale cause de mortalité et d'évolution neurologique défavorable ${ }^{3-5,13}$. En effet, trois séries de cas se basant sur des données autopsiques, l'examen clinique et les données d'imagerie pré-mortem retrouvent l'anoxie comme principale cause de décès ${ }^{3-5}$. Ces mêmes études retrouvent la possibilité d'association lésionnelle compatible avec ces 3 mécanismes pour un même patient ${ }^{3}$.

Les lésions traumatiques sont incriminées comme cause de mortalité entre 5.4 et $23.5 \%$ selon les séries $^{3-5}$. Dans une série canadienne, on retrouvait chez les patients traumatisés avec un Injury Severity Score (ISS) supérieur à 15, 13\% d'autopsie compatible avec des lésions anoxiques associées ${ }^{3}$. Le traumatisme thoracique est le plus fréquent dans la série canadienne de 204 avalanchés décédés analysés sur 21 ans $^{3}$. Il représente $45.8 \%$ des traumatismes ${ }^{3}$. Parmi ces patients traumatisés thoraciques $52.1 \%$ n'étaient pas ensevelis complètement $^{3}$. La proportion des patients traumatisés est également dépendante du terrain puisque l'on retrouve davantage de décès par traumatisme sur des terrains boisés par rapport à des terrains ouverts ${ }^{3}$. La survenue d'un ACR traumatique au cours d'une avalanche présente un pronostic au moins aussi sombre qu'un ACR traumatique survenant sur la voie publique ${ }^{6}$.

Le troisième mécanisme impliqué est l'hypothermie ${ }^{13}$. Il est rarement cité comme cause fréquente de mortalité, notamment par les séries autopsiques ${ }^{3}$. Dans tous les cas, l'hypothermie est fréquemment associée aux lésions d'anoxie ou de traumatisme ${ }^{3}$. Deux études rétrospectives et plusieurs case reports supportent le fait qu'une survie est possible en cas d'ACR par hypothermie profonde si les VAS sont libres ${ }^{8,11,14-17}$. Cette condition est donc rare mais comme précédemment démontrée, à des températures corporelles basses un ACR de plus de 5 minutes est possible sans lésions neurologique ${ }^{7,8,15,17}$. La survie sans séquelle neurologique des patients victimes d'ACR par hypothermie sévère peut atteindre jusqu'à $60 \%$ selon les séries lorsque ces patients bénéficient d'une ECLS ${ }^{17-21}$. Concernant les populations d'avalanchés, le pronostic est beaucoup plus sombre. En effet, la survie sans séquelle neurologique est évaluée de 4 à $15 \%$ selon les séries ${ }^{11,18,19}$. Ces données corroborent le fait 
qu'un ACR survenant dans un contexte d'avalanche ne s'apparente pas à un ACR survenant exclusivement par hypothermie profonde accidentelle ${ }^{2}$. Dans le contexte de l'avalanche, le dogme «no one is dead until warm and dead » est donc rarement vérifiable comme précédemment écrit par Brugger ${ }^{13}$. L’intrication des trois mécanismes impliqués est une explication à cette différence de pronostic.

\section{B. La durée d'ensevelissement.}

Brugger et al. ont démontré que la durée d'ensevelissement est corrélée à la mortalité (Annexe 1) $)^{2,13}$. En effet, les auteurs ont établi une courbe de survie en fonction de la durée d'ensevelissement à partir de données rétrospectives de 946 patients en Suisse ${ }^{2}$ et 301 patients au Canada ${ }^{3,22}$. Dans les deux cohortes, on observait une évolution de la survie non-linéaire en trois phases bien distinctes. En Suisse, la probabilité de survie à 18 minutes était de $80 \%$ (phase de survie) puis chutait rapidement pour atteindre $70 \%$ à 35 minutes (phase d'asphyxie). Au Canada, la courbe décline plus précocément et plus rapidement puisque la survie est de $77 \%$ à 10 minutes puis de $7 \%$ à 35 minutes. Cette différence de survie s'explique par une mortalité par traumatisme et une densité de la neige plus importante en Amérique du Nord $^{3}$. En effet, la densité de la neige a été rapportée comme étant corrélée à l'hypoxie dans une étude expérimentale sur volontaires sains ${ }^{23}$. A 90 minutes d'ensevelissement, on observe une troisième phase avec un rebond de mortalité, conséquence de l'hypothermie combinée à l'hypoxie et l'hypercapnie ${ }^{2}$. Cependant, après plusieurs heures d'ensevelissement, la mortalité n'atteint pas 100\%. Plusieurs facteurs sont associés à une survie malgré un ensevelissement prolongé au delà de 35 minutes : la présence d'une poche à air ${ }^{23,24}$, l'absence d'élément en faveur d'une inhalation ${ }^{2,8,25-31}$, un refroidissement rapide en rapport avec une hypercapnie ${ }^{23,32}$, la densité de la neige ${ }^{23}$, les caractéristiques individuelles ${ }^{23}$.

Les mécanismes d'ACR évoluent avec la durée d'ensevelissement. Les patients anoxiques sont majoritaires dans la seconde partie de la courbe entre 10 et 35 minutes d'ensevelissement, alors que les patients présentant une hypothermie sévère sont dans la troisième partie de la courbe $\mathrm{e}^{2,13}$. Au delà, la survie n'est possible que dans certaines conditions physiopathologiques et l'ACR survient dans un contexte d'hypothermie potentiellement associé à un devenir neurologique favorable. De ce fait, la durée d'ensevelissement même si elle est statistiquement liée à la mortalité, ne doit pas décourager les équipes pré-hospitalières puisque des possibilités de survie sans séquelle neurologique ont été décrites malgré des durées d'ensevelissement extrêmement prolongées ${ }^{8}$. Notre équipe rapporte deux cas d'ensevelissements exceptionnellement prolongés de 6 et 7 heures 
compliqués d'ACR par hypothermie profonde. Ces deux patients ont présenté une récupération neurologique adintegrum (Annexe 2).

\section{Relation kaliémie-anoxie.}

Six études rétrospectives ainsi que plusieurs case reports supportent le fait qu'une kaliémie élevée est en rapport avec un ACR d'origine anoxique et est associée à une plus grande mortalité ${ }^{9,11,15,16,24,27,33,34}$. Au sein des populations d'avalanchés précédemment étudiées, la valeur de kaliémie au delà de laquelle il n'existe pas de survivant est de 6.4 $\mathrm{mmol} / \mathrm{L}^{9,11}$. Parmi les populations d'ACR par hypothermie sévère déjà publiées, on retient une kaliémie à $11,8 \mathrm{mmol} / \mathrm{L}$ associée à une survie ${ }^{10}$. Cependant, ce dernier cas s'avère litigieux. En effet, il s'agit d'un enfant de 31 mois, dont l'ACR est survenu dans un contexte d'exposition au froid. Il semble donc difficile d'extrapoler ce case report à la population des avalanchés. Par ailleurs, l'analyse des données biologiques peut également être soumise à critique. En dehors de ce cas, la kaliémie la plus haute décrite associée à une survie dans un contexte d'ACR par hypothermie sévère est de $9,5 \mathrm{mmol} / \mathrm{L}^{12}$. Chez les patients victimes d'anoxie, la kaliémie à l'admission serait plus élevée du fait d'une lyse cellulaire en rapport avec une acidose mixte : respiratoire liée à l'hypercapnie et métabolique (profondeur de 1'hypoxémie et défaillance circulatoire $)^{24,27}$. Le seuil de kaliémie fait partie des trois critères (avec la température centrale inférieure à $32^{\circ} \mathrm{C}$ et l'absence de traumatisme) qui motiveront l'implantation d'une $\operatorname{ECLS}^{1,6,9,35,36}$. La plupart des recommandations internationales retiennent une kaliémie seuil de $12 \mathrm{mmol} / \mathrm{L}^{1,6,9,35}$ en dehors des recommandations américaines de l'International Liaison Committee On Resuscitation (ILCOR) qui proposent un intervalle entre 10 et $12 \mathrm{mmol} / \mathrm{L}^{36}$. Pour les raisons évoquées ci dessus, nos équipes ont statué sur une valeur seuil n'excédant pas $10 \mathrm{mmol} / \mathrm{L}$.

\section{Température corporelle.}

La profondeur d'hypothermie n'est pas un facteur indépendant de mortalité des ACR par hypothermie sévère ${ }^{18,19,21,37}$. La vitesse maximale de décroissance de la température corporelle est décrite à $9^{\circ} \mathrm{C} / \mathrm{h}$ lors des ensevelissements par avalanche. Cette donnée permet d'affirmer qu'un patient enseveli ne peut pas présenter une température centrale inférieure à $32^{\circ} \mathrm{C}$ si la durée d'ensevelissement est inférieure à 35 minutes ${ }^{8,9,11,13,36}$. Ceci explique les durées d'ensevelissement retenues par les recommandations internationales guidant le triage pré-hospitalier ${ }^{13}$ (Figure 1). Cette donnée est d'autant plus importante que la fiabilité de la mesure sur le terrain est discutable ${ }^{13}$. Pour les patients présentant une température centrale 
inférieure à $32^{\circ} \mathrm{C}$, une survie sans séquelle neurologique n'est possible qu'en dehors du contexte anoxique ou traumatique. Il n'y a donc pas d'indication de transport sous MCE et d'implantation d'ECLS en cas de température supérieure à $32^{\circ} \mathrm{C}$ ou à défaut d'ensevelissement inférieur à 35 minutes. Dans ce cas une réanimation standard est entreprise $^{13}$. Au delà de 35 minutes d'ensevelissement, l'indication de transport sous MCE est également récusée en cas d'obstruction des VAS ou de traumatisme létal ${ }^{13}$.

Concernant les modalités de recueil de la température corporelle pré-hospitalière, la température oesophagienne est recommandée chez les patients intubés ${ }^{13}$. Ce site de recueil est considéré comme étant le plus fiable. Chez le patient ne présentant pas d'ACR, la prise de température épitympanique est une alternative fiable à condition que le dispositif ne soit pas à infrarouge mais avec une thermistance ${ }^{13}$. A défaut, la prise de température rectale peut être employée avec un niveau de preuve plus bas ${ }^{13}$. En cas d'hypothermie isolée, l'utilisation du système de graduation suisse de l'hypothermie ou «Swiss Staging System» basée sur les troubles de conscience et l'hémodynamique reste encore la méthode la plus fiable en dehors du contexte d'ACR (Annexe 3) $)^{13,35}$.

E. Durée de réanimation.

La durée de réanimation avant retour à une activité circulatoire spontanée (RACS) a déjà été décrite comme étant un facteur associé à la mortalité dans une série de 22 patients hypothermes victimes d'ACR ayant bénéficié d'une $\operatorname{ECLS}^{18}$. Néanmois, dans un contexte d'hypothermie, il a déjà été démontré qu'en dépit de réanimation extrêmement prolongée, une survie sans séquelle neurologique était possible ${ }^{8,15,20,38}$. Ces données doivent donc encourager la poursuite de la réanimation en cas de suspicion d'ACR par hypothermie tout en gardant à l'esprit que le délai entre la prise en charge initiale et l'implantation d'une ECLS doit être le plus court possible ${ }^{18}$.

\section{F. Rythme Cardiaque.}

Une étude rétrospective portant sur 26 patients victimes d'ACR par hypothermie sévère décrit un lien statistique significatif entre le rythme décrit à la prise en charge et le pronostic. En effet, Farstad et al. ont démontré que la présence d'une bradycardie extrême était associée à la survie ${ }^{18}$. Cette cohorte ne comprend qu'un patient victime d'avalanche. Chez l'hypotherme comme chez l'avalanché victime d'ACR, aucune étude ne retrouve une meilleure évolution en cas de trouble du rythme ventriculaire par rapport à une asystolie. 
Un cas clinique récent publié en 2012 d'un patient enseveli avec un dispositif de monitoring de la température transcutanée et de la fréquence cardiaque fait état de la possibilité d'une activité électrique cardiaque prolongée au delà de 253 minutes d'ensevelissement ${ }^{29}$ (Annexe 4). Ce tracé montre une évolution en quatre phases : bradycardie contemporaine du refroidissement dans les 18 premières minutes, suivie d'une tachycardie soutenue entre 18 et 35 minutes, puis d'une nouvelle phase de bradycardie entre 35 et 70 minutes et enfin une dernière phase de tachycardie soutenue avec variabilité importante de la fréquence cardiaque avant un ACR au dégagement. Aucun signe de traumatisme ou d'inhalation n'était relevé. Ce cas clinique nous apporte plusieurs enseignements. D'une part, la nécessité d'effectuer un enregistrement de l'activité cardiaque chez tout patient en ACR potentiellement d'origine hypotherme avant de déclarer le décès chez un avalanché. Encore une fois, ce case report encourage les équipes pré-hospitalières à poursuivre activement les recherches malgré un ensevelissement prolongé.

\section{G. Profondeur d'ensevelissement.}

Le travail rétrospectif de Brugger portant sur une cohorte suisse de 1886 avalanchés a montré que la mortalité était corrélée au degré d'ensevelissement ${ }^{2}$. En effet, en cas d'ensevelissement complet (défini par l'ensevelissement de la tête et du thorax) la mortalité s'élevait à 95.8\% (1103/1151) vs 47.6\% (350/735) en cas d'ensevelissement partiel. Ce travail montre que le degré d'ensevelissement est le facteur indépendant le plus associé à la survie ${ }^{2,13}$.

H. Poche à air, voies aériennes et triple H syndrome.

Plusieurs études rétrospectives et case reports ont décrit une survie malgré un ensevelissement prolongé $e^{1,2,8,9}$. Cette survie prolongée dépend de la liberté des VAS et de la présence d'une poche à $\operatorname{air}^{2,9,13,23}$. L'analyse de la courbe de Brugger montre une augmentation importante de la mortalité dans les 35 premières minutes d'ensevelissement puis décroit ensuite ${ }^{2}$ (Annexe 1). Une étude sur volontaires sains simulant un ensevelissement par avalanche a montré qu'une durée d'ensevelissement de plus de 30 minutes était possible avec des niveaux d'hypoxie compatibles avec la vie pour 39\% d'un effectif de 12 ensevelis (28 tests en cross-over) ${ }^{23}$. Parmi les paramètres influençant le niveau d'hypoxie, cette étude retenait comme statistiquement significatif : le volume de la poche à air, la densité de la neige et les caractéristiques individuelles. Parmi les 39\% de volontaires qui n'échouaient pas avant 20 minutes d'ensevelissement, on constatait l'apparition d'un état d'équilibre en terme 
d'hypoxie et d'hypercapnie (Annexe 5). Pour 5 d'entre eux, l'épreuve a pu être poursuivi jusqu'à 30 minutes. Ces constations suggèrent une interaction entre hypothermie, hypercapnie et hypoxie. Ce concept dénommé « triple H syndrome » pourrait expliquer que chez certains patients et dans certaines conditions d'hématose, la vitesse de refroidissement soit plus rapide et permettent l'établissement des phénomènes de neuroprotection avant l'apparition des lésions d'anoxie cellulaire. Brugger en 2003, suggérait que lorsque la fraction inspirée de dioxyde de carbone $\left(\mathrm{CO}_{2}\right)$ dans la poche à air s'élevait au delà de $6,5 \%$, un état de narcose se développait, responsable d'une diminution du réflexe de frisson et des mouvements volontaires conférant ainsi une diminution du métabolisme cellulaire et retardant ainsi les phénomènes ischémiques ${ }^{23}$. Chez ces patients, on observait une baisse plus rapide de la température centrale contemporaine d'une diminution de la consommation en oxygène $\left(\mathrm{O}_{2}\right)$ de $6 \%$ par degré de température centrale perdue ${ }^{32,39,40}$. Une étude postérieure a ensuite démontré que la vitesse de refroidissement était corrélée au niveau d'hypercapnie (Annexe 6). Il s'agit d'une étude prospective sur 12 volontaires sains ensevelis sous la neige et respirant avec ou sans dispositif d'extraction du $\mathrm{CO}_{2}$ (Annexe 7). La vitesse de refroidissement pouvant varier d'un facteur 2 avec le niveau de capnie $\left(\text { de } 1,3+/-0,5^{\circ} \mathrm{C} \text { à } 0,7+/-0,6^{\circ} \mathrm{C}\right)^{32,39}$ (Annexe 6). Plus récemment en 2013, Paal et Brugger ${ }^{24}$ ont étudié les effets combinés du « triple $\mathrm{H}$ syndrome » dans un modèle porcin d'avalanché respirant dans une poche à air versus un groupe contrôle respirant en air ambiant (Annexe 8). Dans le groupe poche à air, la vitesse de refroidissement, la capnie, la kaliémie étaient plus élevées (Annexe 9). Les niveaux d'hypoxie et de $\mathrm{pH}$ étaient plus bas dans le groupe poche à air (Annexe 9). Le délai aboutissant à l'asystolie était plus court dans le groupe poche à air (Annexe 9). L'auteur en concluait qu'en cas de poche à air, une hypothermie pouvait se développer plus rapidement à la phase précoce d'un ensevelissement en particulier en cas d'hypercapnie mais que la présence d'une poche à air ne garantissait pas l'absence de lésion d'anoxie cellulaire. Cette étude présente de nombreuses limitations en particulier l'effectif limité à $n=8$.

\section{Neuroprotection et hypothermie.}

Expérimentalement, l'induction précoce d'une hypothermie centrale modérée $\left(33{ }^{\circ} \mathrm{C}\right)$ permet une protection neuronale et diminue les lésions cérébrales observées dans la plupart des modèles animaux d'ischémie cérébrale focale ou globale ${ }^{41,42}$. L'effet bénéfique de l'hypothermie ne se limite probablement pas au seul mécanisme de la baisse du métabolisme cérébral. Cet effet neuroprotecteur s'exercerait par plusieurs mécanismes. En protégeant les neurones de l'hypoxie, elle diminue aussi leur consommation en oxygène et pourrait ainsi limiter la production de radicaux libres oxygénés potentiellement toxiques (lésions de 
«réoxygénation») $)^{43}$. Outre ces lésions d'ischémie-reperfusion, il existe également au cours du processus d'ischémie-reperfusion cérébrale une «excitotoxicité» importante, responsable de dégâts cérébraux supplémentaires. Ce phénomène a été mis en évidence expérimentalement par la mesure des concentrations locales en acides aminés neuroexcitateurs sur différents modèles animaux d'arrêts cardiaques réanimés. Ces travaux ont permis de montrer qu'il existe une libération massive d'acides aminés neuro-excitateurs (en particulier de glutamate) par les cellules cérébrales les plus vulnérables ${ }^{44}$. Chez le rat, l'induction d'une hypothermie modérée $\left(33^{\circ} \mathrm{C}\right)$ au cours de l'arrêt cardiaque permet d'inhiber complètement la libération locale de glutamate ${ }^{45}$. Il a également été montré que l'hypothermie diminuait l'activation de la voie des caspases et ses conséquences délétères en terme d'apoptose induite par l'ischémie ${ }^{46,47}$. D'autres mécanismes sont évoqués (diminution de la réponse immune et inflammatoire locale, réduction de la production de radicaux libres oxygénés, protection de la barrière hématoencéphalique), qui participent tous probablement à l'effet bénéfique observé. Chez le chien, les travaux menés par l'équipe de Peter Safar ont rapidement confirmé le bénéfice de l'hypothermie modérée induite précocement, et ont également démontré les effets potentiellement délétères d'une hypothermie trop profonde ${ }^{48}$.

En pratique anesthésique, la chirurgie de la crosse aortique nécessite une intervention au niveau de l'implantation des vaisseaux à destinée cérébrale. Ceci implique la réalisation d'un arrêt circulatoire cérébrale en hypothermie profonde. Cette technique permet d'intervenir sur la crosse aortique avec, dans la plupart des cas, une récupération neurologique adintegrum. Ce modèle d'hypothermie thérapeutique illustre les possibilités de récupération neurologique en cas d'ACR par hypothermie profonde. Les premières applications cliniques de 1 'ACR hypothermique datent de $1953^{49-51}$. Initialement, cette ACR hypothermique est obtenu par refroidissement externe puis, à partir de 1963 au moyen de la circulation extracorporelle (CEC) ${ }^{52,53}$. L'hypothermie induite par la CEC provoque une baisse du métabolisme cellulaire évalué à $7 \% /{ }^{\circ} \mathrm{C}$. A $18^{\circ} \mathrm{C}$ (température à laquelle on réalise l'arrêt circulatoire lors de la chirurgie de la crosse aortique), la consommation en $\mathrm{O}_{2}$ du cerveau $\left(\mathrm{CMRO}_{2}\right)$ est de $40 \%$ par rapport à la valeur en normothermi ${ }^{54}$. Seule l'hypothermie permet la diminution de $50 \%$ du métabolisme cellulaire. En effet, au-delà de la diminution de l'activité électrique $\left(50-60 \%\right.$ de la $\left.\mathrm{CMRO}_{2}\right)$, elle permet également une réduction du métabolisme de base $\left(40-50 \% \mathrm{CMRO}_{2}\right)$ contrairement aux agents pharmacologiques qui n'agissent que sur la partie électrique du métabolisme ${ }^{54,55}$. Cet effet métabolique de l'hypothermie sur le neurone n'explique pas à lui seul la neuroprotection. L'hypothermie induit également une diminution du glutamate (neuromédiateur excitotoxique), une diminution de la synthèse de dopamine ainsi que de la synthèse des récepteurs au NMDA (impliqués dans les phénomènes de mort cellulaire et d'excitotoxicité) ${ }^{55}$. 
Le couplage entre le flux sanguin cérébral et $\mathrm{CMRO}_{2}$ est de $15 / 1$ en normothermie alors qu'il atteint 30/1 en hypothermie profonde. Nous savons que l'électroencéphalogramme devient isoélectrique à $20^{\circ} \mathrm{C}$. En revanche, il existe un seuil d'hypothermie létale. En effet, on estime que les transferts membranaires actifs d'ions sont maintenus jusqu'à $12^{\circ} \mathrm{C}$. En deçà de cette valeur les pompes $\mathrm{Na}+/ \mathrm{K}+$ et $\mathrm{Na}+/ \mathrm{Ca}++$ deviennent inefficientes, responsables alors d'un œdème cérébral diffus et d'une hypertension intracrânienne ${ }^{56,57}$. On ne connait pas de température ni de durée d'ACR pour lesquelles on puisse formellement éliminer l'absence de lésion neurologique ${ }^{56,58,59}$. En revanche, sont établies des courbes de probabilités de survenue d'évènements neurologiques fonction de la durée et de la température de l'ACR ${ }^{56,58,59}$ (Annexe 10). Les lésions neurologiques sont proportionnelles à l'âge et à la durée de $1^{\prime} \mathrm{ACR}^{59}$. Elles peuvent être temporaires ou définitives. Selon les séries, elles ont une incidence de 3 à $24 \%{ }^{59}$. En hypothermie à $18^{\circ} \mathrm{C}$, un arrêt de la perfusion cérébrale pendant 35 minutes n'aura souvent pas de conséquences neurologiques. En revanche, un arrêt d'une heure entraine des séquelles. A cette température, la limite de sécurité se situe certainement à 45 minutes $^{60}$. C'est ce qui est retenu actuellement par la plupart des équipes d'anesthésie.

Dans le contexte d'hypothermie accidentelle, notre équipe rapporte un cas exceptionnel d'ACR. Une Réanimation Cardio-Pulmonaire (RCP) de plus de 5 heures a été conduite chez une patiente de 57 ans présentant une température corporelle centrale de $16,9^{\circ} \mathrm{C}$ à l'admission. L'implantation d'une ECLS a été réalisée. Six mois après son ACR, une Imagerie par Résonance Magnétique (IRM) cérébrale confirme l'absence de lésion ${ }^{15}$. Comme vu précédemment un ACR par hypothermie sévère peut conduire à une évolution neurologique favorable du fait des phénomènes de neuroprotection. Cette «neuroprotection accidentelle» explique un pronostic atteignant jusqu'à $60 \%$ de survie sans séquelle neurologique dans certaines séries d'ACR par hypothermie profonde ${ }^{17-21}$. Dans ce contexte, une réanimation prolongée est donc indiquée.

\section{J. Rescue Collapse et After Drop.}

Le collapsus de recirculation ou « Rescue Collapse » (RC) est défini par la survenue d'un ACR au dégagement et au transport d'un patient victime d'hypothermie profonde ou stade III (Annexe 3). Le RC a été attribué à une défaillance circulatoire liée à une hypovolémie, un trouble du rythme cardiaque déclenché par une intervention extérieure (mobilisation du patient ou pose d'un cathéter veineux central en territoire cave supérieur) et à une majoration du refroidissement. 
L'after drop est défini par la poursuite du refroidissement malgré les thérapeutiques de réchauffement externe (solutés réchauffés, couverture à air pulsé, réchauffement de l'air ambiant). Ce concept n'a été mis en évidence qu'en condition de refroidissement expérimentale en rapport avec une différence entre la température rectale et centrale. En pratique clinique, ce phénomène n’a jamais été observé lors du réchauffement.

K. Les thérapeutiques de réchauffement.

En pratique clinique, les stades d'hypothermie sont gradés selon le « Swiss staging system » (Annexe 3$)^{35}$. Cette classification permet d'évaluer la sévérité de l'hypothermie à partir des signes cliniques neurologiques et circulatoires. En effet, la prise de température sur le terrain étant peu fiable, cette classification permet de s'affranchir des difficultés de mesures $^{35}$. Pour chaque stade, il existe une prise en charge thérapeutique spécifique. Dans le cadre de l'ACR par hypothermie profonde ou hypothermie stade IV, la thérapeutique de référence est l'assistance circulatoire de réchauffement ou ExtraCorporal Life Support $(E C L S)^{35}$. Dans le contexte de l'avalanché, la difficulté est d'identifier l'ACR survenu par hypothermie parmi les trois mécanismes impliqués. Ce dernier relevant d'une ECLS de réchauffement.

L. Détecteurs de Victimes d'Avalanches (DVA) et sac Airbag.

Les DVA ont été développés en 1968 aux Etats-Unis. En Europe, entre 1990 et 2004, leur généralisation a permis de mettre en évidence une réduction significative de la durée d'ensevelissement de 125 minutes à 25 minutes $(P<0.001)$ ainsi qu'une réduction de la mortalité de $70.6 \%$ à $55.2 \%(\mathrm{OR} 0.26, P<0.001)^{61}$. Il a également été démontré que l'emploi d'une pelle et d'une sonde associé au DVA permettait d'améliorer la survie ${ }^{61}$.

Depuis 1991, des dispositifs de type sac airbag ont été développés. En cas d'avalanche, le skieur déclenche manuellement le gonflement d'un ou plusieurs sacs lui permettant de rester en surface de la coulée et d'éviter un ensevelissement complet. Ce dispositif a également montré une réduction de mortalité de $18.9 \%$ à $2.9 \%$ (OR 0.09 , $P=0.026)^{61}$. 
III. Matériel et méthodes.

Nous avons analysé rétrospectivement tous les patients victimes d'ACR au cours d'une avalanche admis au déchocage, depuis 20 ans de 1994 à 2013. Le triage préhospitalier et la réanimation des avalanchés ont été conduits par des praticiens hospitaliers selon les recommandations internationales (Figure 1). A l'admission, l'indication d'ECLS de réchauffement était retenue en fonction des données du bilan d'imagerie de routine (radiographie thoracique, radiographie du bassin et FAST échographie), de la kaliémie centrale et de la température corporelle centrale. Les bilans sanguins étaient prélevés par voie fémorale artérielle ou veineuse. Les patients présentant un traumatisme sévère ou une température corporelle au delà de $32^{\circ} \mathrm{C}$ ne présentaient pas d'indication d'ECLS $S^{1,6,35,36}$. Un seuil de kaliémie de moins de $10 \mathrm{mmol} / \mathrm{L}$ a été retenu comme indication d'ECLS ${ }^{36}$.

Les données ont été analysées à partir du registre du Réseau de Traumatologie Nord Alpin des Urgences (TRENAU). Le TRENAU collecte de façon prospective des données à partir du modèle Utstein ${ }^{62,63}$. Ce registre du TRENAU est reconnu par le Comité National de Protection de la Personne et des Libertés Publiques. Ce comité valide l'accès anonyme aux données des patients par le registre du TRENAU.

Le recueil de données comprenait la durée d'ensevelissement, la liberté des VAS ou la présence d'une poche à air, l'existence d'un collapsus de recirculation ou « Rescue Collapse » (RC) à l'extraction, des signes de traumatisme, la température corporelle centrale, un RACS, un transport sous MCE, la durée de RCP, les examens complémentaires et traitements reçus, la réalisation d'un prélèvement multi-organes. A l'admission, les données biologiques plasmatiques suivantes ont été collectées : kaliémie, natrémie, urémie, créatininémie, Pression Partielle artérielle en dioxygène $\left(\mathrm{PaO}_{2}\right)$, Pression Partielle artérielle en dioxyde de carbone $\left(\mathrm{PaCO}_{2}\right), \mathrm{pH}$ artériel, lactates, bicarbonates, troponines I cardiaques, creatine kinase, hémoglobine, thrombocyte, ratio de Temps de Céphaline Activée (TCA ratio), Taux de Prothrombine (TP), fibrinogène. Au décours de la prise en charge au déchocage ou en réanimation, nous avons séparé la population en survivants et non-survivants afin de procéder à l'analyse statistique. L'évolution neurologique a été évaluée à partir du score de performance cérébrale (CPC score) à 3 mois validé dans le cadre de l'évaluation neurologique des patients ayant présenté un $\mathrm{ACR}^{64}$ (Annexe 11). Une bonne évolution neurologique est définie par un score CPC de 1 ou 2.

Les données étaient exprimées en médianes et interquartiles $\left(25-75^{\mathrm{eme}}\right.$ percentiles). Les variables catégorielles étaient comparées en utilisant un test du Chi2. Les variables continues étaient analysées à partir du test non-paramétrique Mann-Witney. Le logiciel StatView a permis l'analyse des données (StatView SE program, SAS institute, Cary, NC). 
Nous n'avons pu réaliser qu'une analyse univariée du fait du nombre limité de patients.

Les données statistiques étaient considérées significatives pour $\mathrm{p}<0,05$. 
Figure 1. Algorithme préhospitalier de prise en charge du patient avalanché en ACR.

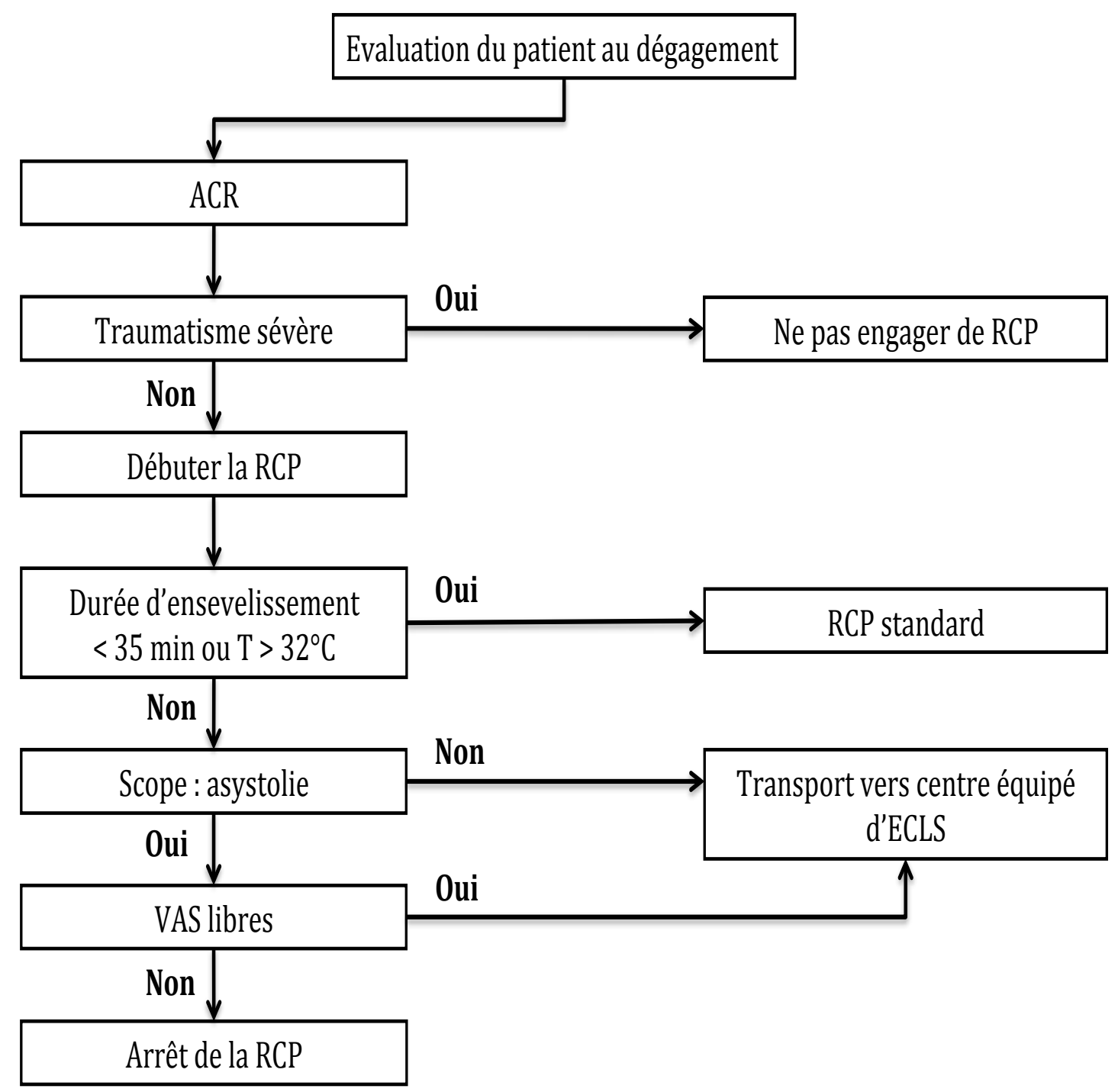

ACR : Arrêt CardioRespiratoire; RCP : Réanimation CardioPulmonaire; T: Température corporelle; ECLS : ExtraCorporal Life Support; VAS : Voies Aériennes Supérieures. 
IV. Résultats.

Soixante-dix patients avalanchés ont été admis au déchocage pendant la période étudiée. Vingt-deux patients ont été exclus car ils n'avaient pas présenté d'ACR. Quarantecinq patients ont été admis au CHU de Grenoble et 3 au CHR d'Annecy. Les caractéristiques générales préhospitalières figurent dans le Tableau 1. La majorité des patients était des hommes jeunes ensevelis 45 minutes. La durée médiane de RCP était de 90 minutes. Huit patients présentaient des signes vitaux définis par la présence d'une respiration spontanée, un pouls carotidien perceptible, une activité électrique cardiaque ou des signes de conscience constatés à la prise en charge initiale. Cependant, 30 patients ont été transportés au déchocage sous MCE, sans RACS.

Les caractéristiques générales de la population à l'admission au déchocage sont récapitulées dans le Tableau 2. Tous les patients présentaient une acidose métabolique profonde mais leur kaliémie artérielle dépassaient le seuil de $12 \mathrm{mmol} / \mathrm{L}$ pour seulement 4 des 48 patient admis. Parmi les 18 patients présentant un RACS, 2 patients ont nécessité l'implantation d'une ECLS du fait d'une instabilité hémodynamique persistante après réanimation standard et tentative de réchauffement externe (Figure 2). Des 30 patients présentant un ACR réfractaire, 19 présentaient une indication d'ECLS à l'admission. En effet, l'arrêt de la réanimation a été retenue du fait d'une kaliémie supérieure à $10 \mathrm{mmol} / \mathrm{L}$ pour 9 patients, d'un traumatisme thoracique sévère pour un patient et d'une température centrale au dessus de $32^{\circ} \mathrm{C}$ pour un patient. Ces patients ont été retirés de l'analyse de survie.

La survie au décours de la prise en charge au déchocage ou en réanimation a donc été évaluée pour 19 patients ayant bénéficié d'une ECLS et 18 patients avec un RACS préhospitalier soit 37 patients au total. Parmi ces patients, 8 ont survécu et sont sortis de réanimation. Le principal mécanisme d'ACR était l'anoxie dans 27 cas, le traumatisme pour 5 patients et l'hypothermie pour 3 patients. La cause de l'ACR n'a pu être déterminée entre asphyxie et traumatisme pour 2 patients du fait d'une dysfonction d'ECLS pour l'un et d'un manque de données d'imagerie pour l'autre. Les principales causes de décès étaient la mort encéphalique $(n=11)$ par œè̀me cérébral et la défaillance multi-viscérale $(n=8)$ (Tableau 3). Le Tableau 4 décrit les résultats de l'analyse univariée pour 8 survivants et 29 patients décédés. Les non-survivants présentaient une durée de RCP plus prolongée, une kaliémie plus haute, un $\mathrm{pH}$ artériel plus bas et plus de troubles de coagulation par rapport aux survivants. On ne retrouvait pas de différence entre les 2 groupes concernant la durée d'ensevelissement et la température centrale pré-hospitalière.

Parmi les 8 survivants, le score CPC à 3 mois était de 1 pour 3 patients, de 3 pour un patient et de 4 pour les 3 autres. Les patients présentant une évolution neurologique favorable 
ont tous bénéficié d'une ECLS du fait d'un ACR réfractaire. Ces 3 patients présentaient tous des signes de vie avant ACR et étaient ensevelis avec une poche à air. Par ailleurs, ils présentaient une durée médiane d'ensevelissement significativement plus élevées que les nonsurvivants traités par ECLS : 390 min (375-405) vs. 50 min IQR (27-75), respectivement (P= 0.03). Deux d'entre eux ont présenté des durées d'ensevelissement exceptionnelles de 6 et 7 heures (Annexe 2).

Huit prélèvements multi-organes ont pu être effectués dans le groupe ayant un RACS contre 2 chez les patients ayant bénéficié d'une ECLS.

Nous avons également analysé les facteurs associés à la survie dans la population d'ACR réfractaires traités par ECLS. Les données sont récapitulées dans le Tableau 5.

Dans ce groupe nous avons pu mettre en évidence que les critères «signes de vie » et « Rescue Collapse » étaient significativement associés aux survivants tandis que la présence d'une asystolie à la prise en charge pré-hospitalière était associée aux non-survivants. Pour les autres paramètres, nous retrouvons les mêmes associations statistiques décrites précédemment pour la population totale des $37 \mathrm{ACR}$. 
Tableau 1. Caractéristiques générales pré-hospitalières de la population ( $\mathrm{n}=48$ patients).

\begin{tabular}{|c|c|}
\hline Variables & Valeurs \\
\hline Age (années) & $33(22-41)$ \\
\hline Sexe masculin (nombre) & 38 \\
\hline Température corporelle $\left({ }^{\circ} \mathrm{C}\right)$ & $28.0(26.0-30.7)$ \\
\hline Durée d'ensevelissement (min) & $43(25-76)$ \\
\hline Maximum no flow (min) & $35(20-65)$ \\
\hline Durée de RCP (min) & $90(18-127)$ \\
\hline \multicolumn{2}{|c|}{ Rythme cardiaque pré-hospitalier (nombre) } \\
\hline Asystolie & 38 \\
\hline Fibrillation ventriculaire & 2 \\
\hline Dissociation électromécanique & 4 \\
\hline Bradycardie extrême & 4 \\
\hline Rescue collapse (nombre) & 6 \\
\hline RACS (nombre) & 18 \\
\hline Transport sous MCE (nombre) & 30 \\
\hline Signes de vie (nombre) & 8 \\
\hline Signes de traumatisme (nombre) & 8 \\
\hline Obstruction des VAS (nombre) & 2 \\
\hline Poche à air (nombre) & 5 \\
\hline
\end{tabular}

Valeurs exprimées en médiane et écart interquartile. RCP, Réanimation CardioPulmonaire;

RACS, Retour à une Activité Cardiaque Spontanée; VAS : Voies Aériennes Supérieures 
Tableau 2. Caractéristiques générales des patients à l'admission hospitalière ( $\mathrm{n}=48$ patients)

\begin{tabular}{|c|c|}
\hline Variables & Valeurs \\
\hline ECLS (nombre) & 21 \\
\hline Kaliémie (mmol/L) & $5.6(4.0-8.6)$ \\
\hline Natrémie (mmol/L) & $143(138-147)$ \\
\hline pH Artériel & $6.9(6.6-7.1)$ \\
\hline $\mathrm{PaCO}_{2}(\mathrm{mmHg})$ & $54.7(36.1-146.6)$ \\
\hline $\mathrm{PaO}_{2}(\mathrm{mmHg})$ & $343.4(80.8-560.9)$ \\
\hline Bicarbonate plasmatique (mmol/L) & $9.9(5-13.8)$ \\
\hline Lactate plasmatique $(\mathrm{mmol} / \mathrm{L})$ & $13.2(8.8-15.6)$ \\
\hline Hemoglobine $(\mathrm{g} / \mathrm{L})$ & $143(119-156)$ \\
\hline Plaquettes (G/L) & $146(119-192)$ \\
\hline TCA ratio & $2.42(1.5-3.6)$ \\
\hline ТР $(\%)$ & $41(23-56)$ \\
\hline Fibrinogène plasmatique $(\mathrm{g} / \mathrm{L})$ & $1.3(0.7-1.8)$ \\
\hline Créatininémie $(\mu \mathrm{mol} / \mathrm{L})$ & $142(116-174)$ \\
\hline Glycémie (mmol/L) & $15.1(11.3-18.6)$ \\
\hline
\end{tabular}

Valeurs exprimées en médiane et $25^{\text {eme }}-75^{\text {eme }}$ percentiles. ECLS : ExtraCorporal Life Support;

TCA : Temps de Céphaline Activée; TP : Taux de Prothrombine 
Figure 2. Organigramme de la population.

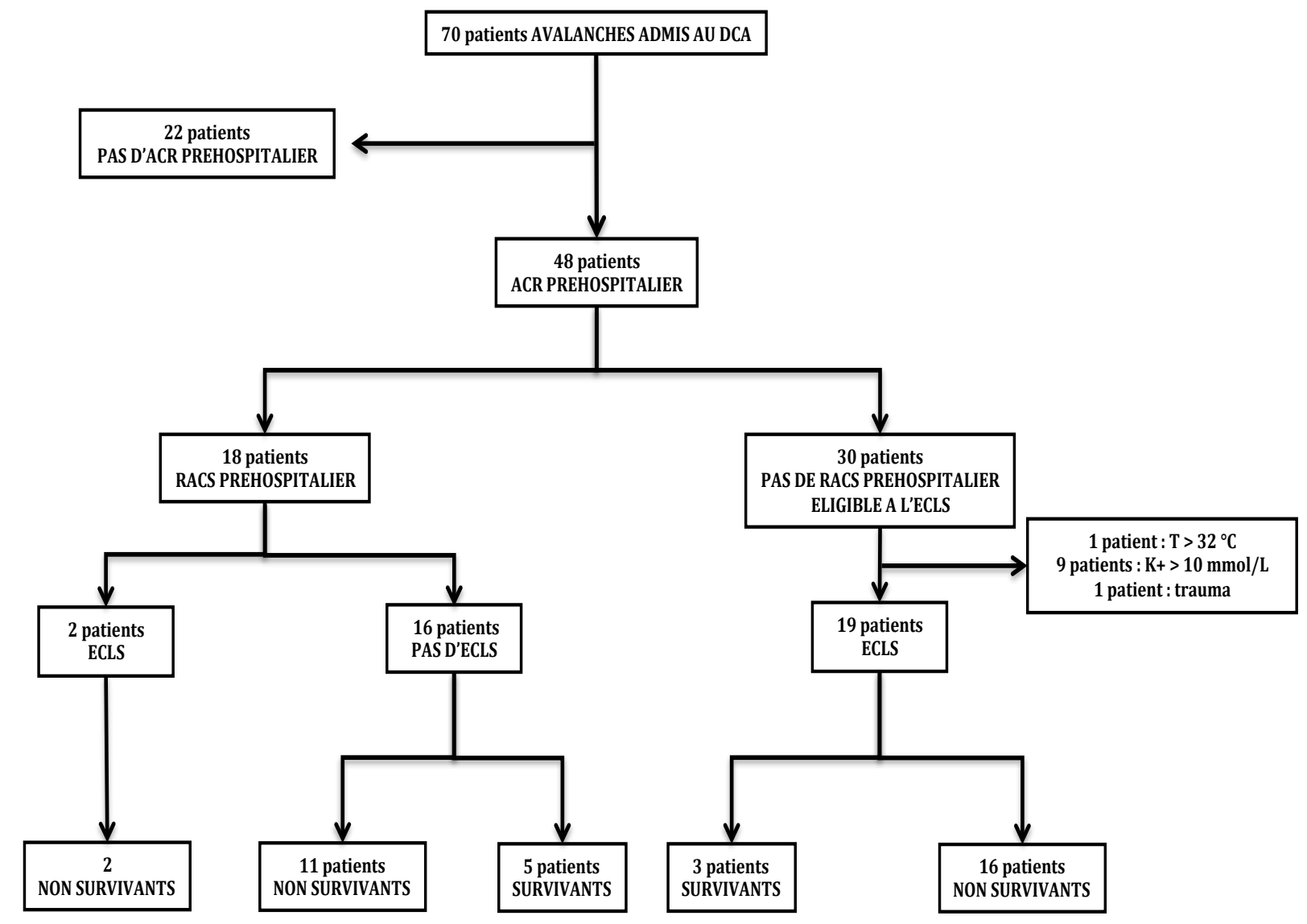

DCA : Déchocage; RACS : Reprise d'une Activité Cardiaque Spontanée; ECLS : ExtraCorporal Life Support; K+ : kaliémie. 
Tableau 3. Causes de mortalité.

\begin{tabular}{lll}
\hline & Groupe RACS & $\begin{array}{l}\text { Groupe ECLS } \\
\mathrm{n}=13\end{array}$ \\
\hline Défaillance multiviscérale & 2 & 6 \\
Mort Encéphalique & 11 & 5 \\
Traumatisme & 0 & 3 \\
Limitation thérapeutique & 0 & 1 \\
Dysfonction d'ECLS & - & 1 \\
\hline
\end{tabular}

RACS : Reprise d'une Activité Cardiocirculatoire Spontanée; ECLS : ExtraCorporal Life Support. 
Table 4. Analyse univariée comparant les non-survivants ( $n=29$ patients) et les survivants à la sortie de réanimation ( $\mathrm{n}=8$ patients $)$.

\begin{tabular}{|c|c|c|c|}
\hline Variables & $\begin{array}{l}\text { Non-survivants } \\
n=29\end{array}$ & $\begin{array}{l}\text { Survivants } \\
n=8\end{array}$ & $\mathrm{P}$ \\
\hline Age (années) & $32(22-43)$ & $37.5(30.5-40.3)$ & 0.77 \\
\hline Sexe masculin (nombre) & 22 & 7 & 0.48 \\
\hline T corporelle préhospitalière $\left({ }^{\circ} \mathrm{C}\right)$ & $28.0(26.8-30.7)$ & $26.5(24.7-28.1)$ & 0.12 \\
\hline Durée d'ensevelissement (min) & $35(25-58)$ & $25(20-203)$ & 0.89 \\
\hline No flow Maximum (min) & $35(23-50)$ & $20(0-21)$ & 0.01 \\
\hline Durée de RCP (min) & $95(20-133)$ & $13(7-26)$ & 0.01 \\
\hline \multicolumn{4}{|c|}{ Rythme cardiaque préhospitalier (nombre) } \\
\hline Asystolie & 24 & 5 & 0.23 \\
\hline Fibrillation ventriculaire & 1 & 0 & 0.60 \\
\hline Dissociation électromécanique & 3 & 0 & 0.58 \\
\hline Bradycardie extrême & 1 & 3 & 0.01 \\
\hline Rescue collapse (nombre) & 3 & 3 & 0.07 \\
\hline Signes de vie préhospitalier (nombre) & 4 & 3 & 0.13 \\
\hline Traumatisme sévère (nombre) & 5 & 2 & 0.62 \\
\hline Obstruction des VAS (nombre) & 2 & 0 & 0.45 \\
\hline Poche à air (nombre) & 2 & 3 & 0.06 \\
\hline ECLS (nombre) & 18 & 3 & 0.38 \\
\hline Kaliémie (mmol/L) & $5.6(4.2-8.0)$ & $3.2(2.7-4.0)$ & 0.001 \\
\hline Natrémie (mmol/L) & $144(139-147)$ & $137(136-139)$ & 0.003 \\
\hline $\mathrm{pH}$ Arterial & $6.81(6.60-7.00)$ & $7.18(7.13-7.19)$ & 0.01 \\
\hline $\mathrm{PaCO}_{2}(\mathrm{mmHg})$ & $57(38-137)$ & $37(35-54)$ & 0.29 \\
\hline $\mathrm{PaO}_{2}(\mathrm{mmHg})$ & $514(372-654)$ & $133(54-439)$ & 0.01 \\
\hline Bicarbonate (mmol/L) & $9(5-12)$ & $15(10-18)$ & 0.01 \\
\hline Lactate (mmol/L) & $13.9(10.8-16.3)$ & $9.1(6.9-12.6)$ & 0.07 \\
\hline Hemoglobine (g/L) & 139 (116-157) & $147(126-154)$ & 0.70 \\
\hline Plaquettes (Giga/L) & $145(106-188)$ & $160(132-214)$ & 0.27 \\
\hline TCA ratio & $3.3(1.9-3.7)$ & $1.3(0.9-1.9)$ & 0.01 \\
\hline ТP $(\%)$ & $30(19-51)$ & $64(54-83)$ & 0.01 \\
\hline Fibrinogène (g/L) & $1.1(0.6-1.7)$ & $1.7(1.6-2.3)$ & 0.04 \\
\hline Creatine kinase (IU/L) & $817(548-1847)$ & $726(579-2253)$ & 0.90 \\
\hline Troponine I cardiaque $(\mu \mathrm{g} / \mathrm{L})$ & $0.31(0.06-0.41)$ & $0.04(0.02-0.17)$ & 0.03 \\
\hline Creatinine $(\mu \mathrm{mol} / \mathrm{L})$ & $144(129.5-182.5)$ & $96(81-133)$ & 0.02 \\
\hline
\end{tabular}

Valeurs exprimées en médiane et $25^{\text {ème }}-75^{\text {ème }}$ percentiles. T : Température; RCP :

Réanimation Cardiopulmonaire; VAS : Voies Aériennes Supérieures; ECLS : ExtraCorporal Life Support ;CEC : Circulation ExtraCorporelle ; TCA : Temps de Céphaline Activée; TP : Taux de Prothrombine. 
Table 5. Analyse univariée des patients traités par ECLS pour ACR réfractaire comparant les non-survivants ( $\mathrm{n}=29$ patients) et les survivants à la sortie de réanimation $(\mathrm{n}=8$ patients).

\begin{tabular}{|c|c|c|c|}
\hline Variables & $\begin{array}{l}\text { Non-survivants } \\
\mathrm{n}=16\end{array}$ & $\begin{array}{l}\text { Survivants } \\
\mathrm{n}=3\end{array}$ & $\mathrm{P}$ \\
\hline Age (années) & $33(22-41)$ & $36(27-39)$ & 0.87 \\
\hline Sexe masculin (n) & 14 & 2 & 0.40 \\
\hline $\mathrm{T}$ corporelle pré-hospitalière $\left({ }^{\circ} \mathrm{C}\right)$ & $27.9(25.5-30)$ & $23.3(22.7-25.1)$ & 0.15 \\
\hline Durée d’ensevelissement (min) & $50(28-75)$ & $390(375-405)$ & 0.03 \\
\hline No flow maximum (min) & $50(25-63)$ & 0 & 0.01 \\
\hline Durée de RCP (min) & $127(106-159)$ & $45(23-50)$ & 0.01 \\
\hline \multicolumn{4}{|c|}{ Rythme cardiaque pré-hospitalier (nombre) } \\
\hline Asystolie & 14 & 0 & 0.002 \\
\hline Fibrillation ventriculaire & 0 & 0 & \\
\hline Dissociation électromécanique & 1 & 0 & 0.61 \\
\hline Bradycardie extrême & 1 & 3 & 0.001 \\
\hline Rescue collapse (nombre) & 2 & 3 & 0.01 \\
\hline Signes de vie pré-hospitaliers (nombre) & 4 & 3 & 0.01 \\
\hline Traumatisme pré-hospitalier (nombre) & 5 & 1 & 0.94 \\
\hline Obstruction des VAS (nombre) & 1 & 0 & 0.67 \\
\hline Poche à air (nombre) & 2 & 3 & 0.002 \\
\hline Durée d'ECLS (h) & $2(1.9-11.6)$ & $3.3(2.4-25.7)$ & 0.54 \\
\hline Vitesse de réchauffement $\left({ }^{\circ} \mathrm{C} / \mathrm{h}\right)$ & $3.35(1.2-5.8)$ & $4.6(4.3-5.1)$ & 0.54 \\
\hline CEC (nombre) & 6 & 1 & 0.90 \\
\hline Kaliémie (mmol/L) & $6.4(5.5-8.3)$ & $2.8(2.7-3.3)$ & 0.01 \\
\hline Natrémie (mmol/L) & $146(143-150)$ & $136(136-138)$ & 0.01 \\
\hline $\mathrm{pH}$ artérielle & $6.73(6.50-7.00)$ & $7.19(7.18-7.23)$ & 0.02 \\
\hline $\mathrm{PaCO}_{2}(\mathrm{mmHG})$ & $101(45-160)$ & $54(45-55)$ & 0.21 \\
\hline $\mathrm{PaO}_{2}$ in $(\mathrm{mmHG})$ & $86(42-332)$ & $334(317-499)$ & 0.14 \\
\hline Bicarbonate (mmol/L) & $9(5-11)$ & $19(17-20)$ & 0.01 \\
\hline Lactate (mmol/L) & $14.2(11.8-15.7)$ & $7(6.1-9.5)$ & 0.06 \\
\hline Hemoglobine (g/L) & $134(106-147)$ & $118(95-132)$ & 0.50 \\
\hline Plaquettes (Giga/L) & $111(88-137)$ & $132(132-143)$ & 0.13 \\
\hline TCA ratio & $3.6(3.5-3.9)$ & $1.31(1.3-2.1)$ & 0.02 \\
\hline $\mathrm{TP}(\%)$ & $27(11-31)$ & $58(41-70)$ & 0.11 \\
\hline Fibrinogène $(\mathrm{g} / \mathrm{L})$ & $0.9(0.6-1.2)$ & $1.6(1.3-1.9)$ & 0.12 \\
\hline Creatine kinase (IU/L) & $948(548-2024)$ & $742(564-1880)$ & 0.90 \\
\hline Troponine I cardiaque $(\mu \mathrm{g} / \mathrm{L})$ & $0.32(0.09-0.67)$ & $0.02(0.02-0.03)$ & 0.02 \\
\hline Urée $(\mathrm{mmol} / \mathrm{L})$ & $7.2(6.7-8.4)$ & $8.1(7.9-8.5)$ & 0.28 \\
\hline Creatinine $(\mu \mathrm{mol} / \mathrm{L})$ & $150(143-184)$ & $75(69-79)$ & 0.01 \\
\hline
\end{tabular}

Valeurs exprimées en médiane et $25^{\text {ème }}-75^{\text {ème }}$ percentiles. $\mathrm{T}:$ Température; RCP : Réanimation Cardiopulmonaire; VAS : Voies Aériennes Supérieures; ECLS : ExtraCorporal Life Support ;CEC : Circulation ExtraCorporelle; TCA : Temps de Céphaline Activée; TP : Taux de Prothrombine. 
V. Discussion.

Notre travail représente la plus importante série d'avalanchés victimes d'ACR admis dans un déchocage de niveau $\mathrm{I}^{11,18,19,27}$. Seulement 8 patients sur 48 ont survécu et 3 patients ont présenté une évolution neurologique favorable à 3 mois de l'ACR par ensevelissement. A l'admission hospitalière, la survenue de troubles de coagulation et d'une hyperkaliémie étaient associés à la mortalité alors que les patients ayant présenté des signes de vie préhospitalier et une poche à air ont montré une évolution neurologique favorable.

Dans notre série, la survie globale est de 17\%. Cette donnée est proche des publications précédentes portant sur des victimes avalanchés en $\mathrm{ACR}^{11,19}$. Ceci confirme que le pronostic des ACR survenant dans un contexte d'ensevelissement par avalanche est nettement plus sombre que celui des ACR par hypothermie accidentelle ${ }^{15,17-21,35,38,65-67}$. L'importance du phénomène anoxique est probablement impliquée dans cette différence de mortalité. En effet, dans $71 \%$ des cas (n=34), l'anoxie est impliquée dans la cause de l'ACR. Comme précédemment décrit par d'autres études, il s'agit de la première cause d'ACR dans notre série ${ }^{3-5,13}$. Par ailleurs, cette donnée contraste avec la faible incidence des signes préhospitaliers d'obstruction des VAS estimée à 4\% $(n=2)$ dans notre cohorte. L'obstruction des VAS est donc un signe peu fiable d'évaluation de la cause de l'ACR en pré-hospitalier dans ce contexte d'ensevelissement par avalanche. Ces données sont également instructives en matière de médecine de catastrophe et de scénario multi-victimes dans le but de prioriser l'évacuation des patients avalanchés. La probabilité d'une évolution neurologique favorable étant très faible, l'avalanché victime d'ACR ne sera pas évacué prioritairement même si le mécanisme hypothermie est potentiellement impliqué.

Lors de la prise en charge pré-hospitalière, la présence de signes de vie avant l'ACR est associée à une excellente récupération neurologique à savoir un score CPC de à 1 à 3 mois malgré la survenue d'un RC. Ce RC est défini par un «ACR survenant au dégagement et à la mobilisation du patient victime d'hypothermie sévère ». Ce phénomène physiopathologique correspond à une défaillance circulatoire par hypovolémie, troubles du rythme cardiaque à la mobilisation et à une majoration du refroidissement corporel ${ }^{16,35}$. Néanmoins, ce phénomène a également été observé chez 3 patients décédés. Comme préalablement décrit, la survenue d'un RC n'est donc pas une condition suffisante garantissant une évolution neurologique favorable ${ }^{29}$. Dans notre cohorte, la présence d'une poche à air était associée à la survie comme décrit par les études précédentes ${ }^{2,25,32,68}$. En résumé, la présence de signes de vie et d'une poche à air sont des marqueurs pré-hospitaliers évocateurs d'ACR par hypothermie sévère et pourraient être associés à une évolution neurologique favorable. 
Dans notre étude, la durée d'ensevelissement n'est pas associée au pronostic des patients. Ceci peut s'expliquer grâce à la courbe de survie décrite par Brugger. En effet, comme décrit par l'auteur, l'étiologie hypothermie est d'autant plus impliquée que la durée d'ensevelissement est prolongée. Cette condition ne concerne qu'une faible proportion d'avalanchés mais représente la meilleure chance d'évolution neurologique favorable ${ }^{7-9,17}$. Dans notre cohorte, deux survivants ont présenté des durées d'ensevelissement exceptionnelles de 7 et 6 heures. Pour les équipes pré-hospitalières et de secouristes, ces données illustrent donc la nécessité de poursuivre activement les recherches malgré des durées d'ensevelissement importantes (Annexe 2).

Comme précédemment publié, une kaliémie élevée à l'admission est associée à la mortalitê $8,10-12,15,27,34$. Dans notre cohorte, la kaliémie la plus élevée retrouvée chez les survivants est de $4.2 \mathrm{mmol} / \mathrm{L}$. En prenant en compte les 48 patients à l'admission, seulement 4 patients ont présenté une kaliémie au-delà de $12 \mathrm{mmol} / \mathrm{L}$. Dans une étude rétrospective portant sur 32 patients avalanchés, la kaliémie était de $4.25 \pm 4.9 \mathrm{mmol} / \mathrm{L}(3.1-6.4 \mathrm{mmol} / \mathrm{L})$ chez les survivants et de $9.95 \pm 4.9 \mathrm{mmol} / \mathrm{L}(2.0-18 \mathrm{mmol} / \mathrm{L})$ chez les non-survivants $(\mathrm{P}=0.003)^{11}$. Actuellement, les recommandations internationales retiennent une indication d'ECLS jusqu'à des valeurs de kaliémie comprise entre 10 et $12 \mathrm{mmol} / \mathrm{L}^{6,9,13,35,36}$. Notre travail, concernant les kaliémies plasmatiques retrouvées, suggère de rediscuter à la baisse les seuils de kaliémie retenus par les recommandations internationales.

Par ailleurs, nous retrouvons une incidence plus importante de troubles de coagulation chez les non-survivants. A notre connaissance, il n'existe pas de donnée publiée chez l'avalanché concernant ces anomalies biologiques. Ces données sont d'autant plus intéressantes qu'elles présentent une pertinence statistique. En effet, concernant le TP, on ne retrouve pas de zone de chevauchement entre survivants et non-survivants. Une étude récente a mis en évidence des marqueurs de coagulation intravasculaire disséminée associés à une défaillance multiviscérale dans une population de $52 \mathrm{ACR}$ extrahospitaliers ${ }^{69}$. Une autre étude récente portant sur 250 patients victimes d'ACR extrahospitaliers a mis en évidence une association entre coagulopathie, mortalité et devenir neurologique ${ }^{70}$. L'activation de la coagulation via la survenue d'un syndrome post-ACR pourrait rendre compte de cette association statistique péjorative entre mortalité et troubles de coagulation ${ }^{68,69}$. La généralisation des moyens de biologie délocalisée pourrait permettre d'intégrer les troubles de coagulation à l'algorithme de triage en association avec la mesure de la kaliémie.

Néanmoins, notre étude présente plusieurs limites. Premièrement, il s'agit d'une étude rétrospective impliquant des biais en particulier sur l'évolution des pratiques médicales durant cette période d'étude s'étendant sur 20 ans. Dans cette optique, nous avons mis en place un registre régional des avalanchés à l'aide du Réseau de Traumatologie Nord Alpin des 
Urgences. Ce registre, dénommé Registre Nord Alpin des AValanchés (RENAAV), nous permet de recueillir de façon prospective les données des patients avalanchés relevant d'une prise en charge médicale. Deuxièmement, nous n'avons pas pu réaliser d'analyse multivariée en vue de mettre en évidence des facteurs indépendants de survie. Du fait d'un nombre trop restreint de survivants ( $\mathrm{n}=8$ patients), il n'a pas été possible de réaliser cette analyse statistique. De plus, notre effectif global est également trop restreint et nos données méritent donc d'être confirmées par une cohorte plus large. Troisièmement, la mesure des troubles de coagulation au lit du patient n'est pas une pratique courante dans tous les centres de traumatologie et la disponibilité de ces techniques est encore restreinte. Ceci pourrait représenter un obstacle à l'introduction des troubles de coagulation comme paramètre de triage des victimes d'avalanches. 
VI. Conclusion.

L'ACR après ensevelissement complet par avalanche représente un pronostic sombre. Dans une série de 48 patients victimes d'ACR admis dans un déchocage de niveau I de deux centres hospitaliers des Alpes françaises du Nord, seulement 8 patients ont survécu et 3 ont présenté une évolution neurologique favorable 3 mois après l'ensevelissement. A l'accueil de ces patients, la recherche des critères pronostiques est essentielle afin d'orienter la décision médicale vers une réanimation prolongée. Nos données suggèrent que des paramètres préhospitaliers et biologiques à l'admission pourraient optimiser le triage des patients avalanchés en ACR en vue d'une réanimation prolongée. 
THESE SOUTENUE PAR : Yvonnick BOUE

\section{TITRE :}

\section{Analyse de la survie des patients avalanchés en arrêt cardiaque dans les Alpes du Nord.}

\section{CONCLUSION}

Introduction: Pathologie circonstancielle fréquente dans notre région, la prise en charge des avalanchés pose le problème du triage des patients victimes d'arrêt cardiaque $(\mathrm{AC})$ réfractaire consécutivement à un ensevelissement complet. En effet, 3 mécanismes peuvent conduire à un $\mathrm{AC}$ dans ce contexte: l'anoxie, le traumatisme ou l'hypothermie. Seul l'AC par hypothermie sévère permet d'espérer une évolution neurologique favorable. En cas d'AC réfractaire, les critères actuels d'éligibilité à l'assistance circulatoire sont dictés par les recommandations internationales : absence d'un traumatisme sévère, température corporelle inférieure à $32^{\circ} \mathrm{C}$ et kaliémie inférieure à $10 \mathrm{mmol} / \mathrm{L}$.

Objectif: Mettre en évidence les facteurs associés à la survie afin d'optimiser le triage des patients avalanchés en AC réfractaire.

Matériel et méthodes: Cette étude rétrospective, observationnelle a été conduite de 1994 à 2013 dans les Alpes du Nord. Elle concerne tous les avalanchés en AC admis au déchocage suite à un ensevelissement par avalanche. Le registre du Réseau de Traumatologie Nord Alpin des Urgences a permis le recueil des données. Le triage pré-hospitalier suivait les recommandations internationales. A l'admission hospitalière, les patients transportés sous massage cardiaque étaient récusés à l'assistance circulatoire devant un traumatisme sévère diagnostiqué au bilan initial, une kaliémie supérieure à $10 \mathrm{mmol} / \mathrm{L}$ ou une température centrale supérieure à $32^{\circ} \mathrm{C}$. Les facteurs associés à la survie hospitalière ont été déterminés par analyse univariée (test de Mann-Whitney). L'évolution neurologique était évaluée par le score Cerebral Performance Category (CPC) à 3 mois. Un score CPC de 1-2 représentant une évolution neurologique favorable.

Résultats : Quarante-huit patients (âge médian 33 ans, durée d'ensevelissement médiane 43 minutes, température corporelle médiane $28^{\circ} \mathrm{C}$ ) ont été inclus. Dix-huit patients présentaient une reprise d'activité circulatoire spontanée en pré-hospitalier. A l'admission hospitalière, 11 patients en $\mathrm{AC}$ réfractaire ont été récusés à l'assistance circulatoire du fait d'une hyperkaliémie ( $\mathrm{n}=8$ patients), d'une température supérieure à $32^{\circ} \mathrm{C}$ ( $\mathrm{n}=2$ patients) ou d'un traumatisme thoracique ( $\mathrm{n}=1$ patient). Vingt et un patients ont bénéficié d'une assistance circulatoire $(n=19)$ ou pour une instabilité hémodynamique persistante $(n=2)$. Huit patients 
ont survécu et seulement 3 ont présenté une évolution neurologique favorable (CPC 1). Les facteurs pré-hospitaliers associés à la survie étaient la présence d'une poche à air lors de l'ensevelissement, de signes de vie avant l'AC (pas d'asystolie, mouvements respiratoires, et/ou score de Glasgow supérieur à 3) et l'existence d'un collapsus de recirculation (rescue collapse) défini par un AC à la mobilisation d'un patient en hypothermie profonde.

La kaliémie était plus élevée dans le groupe des non-survivants (5.6 [4.2-4.8] mmol/L) par rapport aux survivants $(3.2[2.7-4] \mathrm{mmol} / \mathrm{L}, \mathrm{P}=0.001)$. Les non-survivants présentaient davantage de troubles de coagulation que les survivants (Taux de Prothrombine : 64 [54-83] $\%$ vs. 30 [19-51] \%, respectivement, $\mathrm{p}<0.01$ ). Parmi les 3 patients survivants sans séquelle neurologique, 2 ont présenté des durées d'ensevelissement exceptionnellement prolongées de 6 et 7 heures.

Conclusion : Le pronostic des patients victimes d'AC lors d'une avalanche est sombre puisque seulement 3 patients sur 48 ont présenté une évolution neurologique favorable. En pré-hospitalier, la présence d'une poche à air a été associée à la survie ainsi que la présence de signes de vie avant l'AC. La recherche des victimes doit être poursuivie malgré des durées prolongées d'ensevelissement. Avec l'hyperkaliémie, les troubles de coagulation pourraient intégrer l'algorithme de triage pour la mise en place d'une assistance circulatoire en cas d'AC réfractaire.

\section{VU ET PERMIS D'IMPRIMER}

Grenoble, le $7 / 4 / 2014$

\section{LE DOYEN}

JP ROMANET

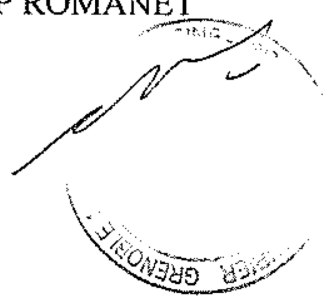

\section{LE PRESIDENT DE LA THESE}

PROFESSEUR JF PAYEN

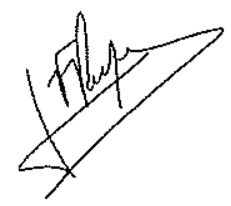


VII. Bibliographie.

1. Brugger H, Durrer B, Elsensohn F, et al. Resuscitation of avalanche victims: Evidence-based guidelines of the international commission for mountain emergency medicine (ICAR MEDCOM): Intended for physicians and other advanced life support personnel. Resuscitation 2012.

2. Brugger H, Durrer B, Adler-Kastner L, Falk M, Tschirky F. Field management of avalanche victims. Resuscitation 2001;51:7-15.

3. Boyd J, Haegeli P, Abu-Laban RB, Shuster M, Butt JC. Patterns of death among avalanche fatalities: a 21-year review. CMAJ : Canadian Medical Association journal = journal de l'Association medicale canadienne 2009;180:507-12.

4. Hohlrieder M, Brugger H, Schubert HM, Pavlic M, Ellerton J, Mair P. Pattern and severity of injury in avalanche victims. High altitude medicine \& biology 2007;8:56-61.

5. McIntosh SE, Grissom CK, Olivares CR, Kim HS, Tremper B. Cause of death in avalanche fatalities. Wilderness \& environmental medicine 2007;18:293-7.

6. Soar J, Perkins GD, Abbas G, et al. European Resuscitation Council Guidelines for Resuscitation 2010 Section 8. Cardiac arrest in special circumstances: Electrolyte abnormalities, poisoning, drowning, accidental hypothermia, hyperthermia, asthma, anaphylaxis, cardiac surgery, trauma, pregnancy, electrocution. Resuscitation 2010;81:140033.

7. Gilbert M, Busund R, Skagseth A, Nilsen PA, Solbo JP. Resuscitation from accidental hypothermia of 13.7 degrees $C$ with circulatory arrest. Lancet 2000;355:375-6.

8. Oberhammer R, Beikircher W, Hormann C, et al. Full recovery of an avalanche victim with profound hypothermia and prolonged cardiac arrest treated by extracorporeal rewarming. Resuscitation 2008;76:474-80.

9. Boyd J, Brugger H, Shuster M. Prognostic factors in avalanche resuscitation: a systematic review. Resuscitation 2010;81:645-52.

10. Dobson JA, Burgess JJ. Resuscitation of severe hypothermia by extracorporeal rewarming in a child. The Journal of trauma 1996;40:483-5.

11. Locher T, Walpoth BH. [Differential diagnosis of circulatory failure in hypothermic avalanche victims: retrospective analysis of 32 avalanche accidents]. Praxis 1996;85:1275-82.

12. von Segesser LK, Garcia E, Turina M. Perfusion without systemic heparinization for rewarming in accidental hypothermia. The Annals of thoracic surgery 1991;52:560-1.

13. Brugger H, Durrer B, Elsensohn F, et al. Resuscitation of avalanche victims: Evidence-based guidelines of the international commission for mountain emergency medicine 
(ICAR MEDCOM): intended for physicians and other advanced life support personnel. Resuscitation 2013;84:539-46.

14. Althaus U, Aeberhard P, Schupbach P, Nachbur BH, Muhlemann W. Management of profound accidental hypothermia with cardiorespiratory arrest. Annals of surgery 1982;195:492-5.

15. Boue Y, Lavolaine J, Bouzat P, Matraxia S, Chavanon O, Payen JF. Neurologic recovery from profound accidental hypothermia after 5 hours of cardiopulmonary resuscitation. Critical care medicine 2014;42:e167-70.

16. Danzl DF, Pozos RS, Auerbach PS, et al. Multicenter hypothermia survey. Annals of emergency medicine 1987;16:1042-55.

17. Walpoth BH, Walpoth-Aslan BN, Mattle HP, et al. Outcome of survivors of accidental deep hypothermia and circulatory arrest treated with extracorporeal blood warming. The New England journal of medicine 1997;337:1500-5.

18. Farstad M, Andersen KS, Koller ME, Grong K, Segadal L, Husby P. Rewarming from accidental hypothermia by extracorporeal circulation. A retrospective study. European journal of cardio-thoracic surgery : official journal of the European Association for Cardio-thoracic Surgery 2001;20:58-64.

19. Ruttmann E, Weissenbacher A, Ulmer H, et al. Prolonged extracorporeal membrane oxygenation-assisted support provides improved survival in hypothermic patients with cardiocirculatory arrest. The Journal of thoracic and cardiovascular surgery 2007;134:594600.

20. Schober A, Sterz F, Handler C, et al. Cardiac arrest due to accidental hypothermia-a 20 year review of a rare condition in an urban area. Resuscitation 2014.

21. Silfvast T, Pettila V. Outcome from severe accidental hypothermia in Southern Finland--a 10-year review. Resuscitation 2003;59:285-90.

22. Haegeli P, Falk M, Brugger H, Etter HJ, Boyd J. Comparison of avalanche survival patterns in Canada and Switzerland. CMAJ : Canadian Medical Association journal = journal de l'Association medicale canadienne 2011;183:789-95.

23. Brugger H, Sumann G, Meister R, et al. Hypoxia and hypercapnia during respiration into an artificial air pocket in snow: implications for avalanche survival. Resuscitation 2003;58:81-8.

24. Paal P, Strapazzon G, Braun P, et al. Factors affecting survival from avalanche burial-a randomised prospective porcine pilot study. Resuscitation 2013;84:239-43.

25. Falk M, Brugger H, Adler-Kastner L. Avalanche survival chances. Nature 1994;368:21. 
26. Grosse AB, Grosse CA, Steinbach LS, Zimmermann H, Anderson S. Imaging findings of avalanche victims. Skeletal radiology 2007;36:515-21.

27. Mair P, Kornberger E, Furtwaengler W, Balogh D, Antretter H. Prognostic markers in patients with severe accidental hypothermia and cardiocirculatory arrest. Resuscitation 1994;27:47-54.

28. Stalsberg H, Albretsen C, Gilbert M, et al. Mechanism of death in avalanche victims. Virchows Archiv A, Pathological anatomy and histopathology 1989;414:415-22.

29. Strapazzon G, Beikircher W, Procter E, Brugger H. Electrical heart activity recorded during prolonged avalanche burial. Circulation 2012;125:646-7.

30. Kornberger E, Mair P. Important aspects in the treatment of severe accidental hypothermia: the Innsbruck experience. Journal of neurosurgical anesthesiology 1996;8:83-7.

31. Radwin MI, Grissom CK. Technological advances in avalanche survival. Wilderness \& environmental medicine 2002;13:143-52.

32. Grissom CK, Radwin MI, Harmston CH, Hirshberg EL, Crowley TJ. Respiration during snow burial using an artificial air pocket. JAMA : the journal of the American Medical Association 2000;283:2266-71.

33. Hauty MG, Esrig BC, Hill JG, Long WB. Prognostic factors in severe accidental hypothermia: experience from the Mt. Hood tragedy. The Journal of trauma 1987;27:1107-12. 34. Schaller MD, Fischer AP, Perret CH. Hyperkalemia. A prognostic factor during acute severe hypothermia. JAMA : the journal of the American Medical Association 1990;264:1842-5.

35. Brown DJ, Brugger H, Boyd J, Paal P. Accidental hypothermia. The New England journal of medicine 2012;367:1930-8.

36. Vanden Hoek TL, Morrison LJ, Shuster M, et al. Part 12: cardiac arrest in special situations: 2010 American Heart Association Guidelines for Cardiopulmonary Resuscitation and Emergency Cardiovascular Care. Circulation 2010;122:S829-61.

37. Vassal T, Benoit-Gonin B, Carrat F, Guidet B, Maury E, Offenstadt G. Severe accidental hypothermia treated in an ICU: prognosis and outcome. Chest 2001;120:19982003.

38. Meyer M, Pelurson N, Khabiri E, Siegenthaler N, Walpoth BH. Sequela-free longterm survival of a 65-year-old woman after 8 hours and 40 minutes of cardiac arrest from deep accidental hypothermia. The Journal of thoracic and cardiovascular surgery 2014;147:e1-2.

39. Grissom CK, McAlpine JC, Harmston CH, et al. Hypercapnia effect on core cooling and shivering threshold during snow burial. Aviation, space, and environmental medicine 2008;79:735-42. 
40. Wood SC. Interactions between hypoxia and hypothermia. Annual review of physiology 1991;53:71-85.

41. Polderman KH. Application of therapeutic hypothermia in the ICU: opportunities and pitfalls of a promising treatment modality. Part 1: Indications and evidence. Intensive care medicine 2004;30:556-75.

42. Sterz F, Holzer M, Roine R, et al. Hypothermia after cardiac arrest: a treatment that works. Current opinion in critical care 2003;9:205-10.

43. Vaagenes P, Ginsberg M, Ebmeyer U, et al. Cerebral resuscitation from cardiac arrest: pathophysiologic mechanisms. Critical care medicine 1996;24:S57-68.

44. Rothman SM, Olney JW. Glutamate and the pathophysiology of hypoxic--ischemic brain damage. Annals of neurology 1986;19:105-11.

45. Busto R, Globus MY, Dietrich WD, Martinez E, Valdes I, Ginsberg MD. Effect of mild hypothermia on ischemia-induced release of neurotransmitters and free fatty acids in rat brain. Stroke; a journal of cerebral circulation 1989;20:904-10.

46. Ning $\mathrm{XH}, \mathrm{Chen} \mathrm{SH}, \mathrm{Xu} \mathrm{CS}$, et al. Hypothermic protection of the ischemic heart via alterations in apoptotic pathways as assessed by gene array analysis. Journal of applied physiology (Bethesda, Md : 1985) 2002;92:2200-7.

47. Xu L, Yenari MA, Steinberg GK, Giffard RG. Mild hypothermia reduces apoptosis of mouse neurons in vitro early in the cascade. Journal of cerebral blood flow and metabolism : official journal of the International Society of Cerebral Blood Flow and Metabolism 2002;22:21-8.

48. Weinrauch V, Safar P, Tisherman S, Kuboyama K, Radovsky A. Beneficial effect of mild hypothermia and detrimental effect of deep hypothermia after cardiac arrest in dogs. Stroke; a journal of cerebral circulation 1992;23:1454-62.

49. Boerema I, Wildschut A, Schmidt WJ, Broekhuysen L. Experimental researches into hypothermia as an aid in the surgery of the heart. Archivum chirurgicum Neerlandicum 1951;3:25-34.

50. Lewis FJ, Taufic M. Closure of atrial septal defects with the aid of hypothermia; experimental accomplishments and the report of one successful case. Surgery 1953;33:52-9.

51. Swan H, Zeavin I, Blount SG, Jr., Virtue RW. Surgery by direct vision in the open heart during hypothermia. Journal of the American Medical Association 1953;153:1081-5.

52. Barnard CN, Schrire V. The surgical treatment of acquired aneurysm of the throracic aorta. Thorax 1963;18:101-15.

53. Borst HG, Schaudig A, Rudolph W. ARTERIOVENOUS FISTULA OF THE AORTIC ARCH: REPAIR DURING DEEP HYPOTHERMIA AND CIRCULATORY ARREST. The Journal of thoracic and cardiovascular surgery 1964;48:443-7. 
54. JD M. The awake brain. New York : Churchill Livingstone; 1988.

55. Sano T, Drummond JC, Patel PM, Grafe MR, Watson JC, Cole DJ. A comparison of the cerebral protective effects of isoflurane and mild hypothermia in a model of incomplete forebrain ischemia in the rat. Anesthesiology 1992;76:221-8.

56. Kern FH, Ungerleider RM, Reves JG, et al. Effect of altering pump flow rate on cerebral blood flow and metabolism in infants and children. The Annals of thoracic surgery 1993;56:1366-72.

57. I R. Hypothermia. Oxford : Butterworth; 1994.

58. JW K. Cardiac Surgery. New York : Churchill Livingston; 1993.

59. Svensson LG, Crawford ES, Hess KR, et al. Deep hypothermia with circulatory arrest. Determinants of stroke and early mortality in 656 patients. The Journal of thoracic and cardiovascular surgery 1993;106:19-28; discussion -31.

60. Martin. Thoracic aortic surgery and cardiopulmonar bypass; 1995.

61. Brugger H, Etter HJ, Zweifel B, et al. The impact of avalanche rescue devices on survival. Resuscitation 2007;75:476-83.

62. Dick WF, Baskett PJ. Recommendations for uniform reporting of data following major trauma--the Utstein style. A report of a working party of the International Trauma Anaesthesia and Critical Care Society (ITACCS). Resuscitation 1999;42:81-100.

63. Dick WF, Baskett PJ, Grande C, et al. Recommendations for uniform reporting of data following major trauma--the Utstein Style. An International Trauma Anaesthesia and Critical Care Society (ITACCS) initiative. European journal of emergency medicine : official journal of the European Society for Emergency Medicine 1999;6:369-87.

64. Phelps R, Dumas F, Maynard C, Silver J, Rea T. Cerebral Performance Category and long-term prognosis following out-of-hospital cardiac arrest. Critical care medicine 2013;41:1252-7.

65. Husby P, Andersen KS, Owen-Falkenberg A, Steien E, Solheim J. Accidental hypothermia with cardiac arrest: complete recovery after prolonged resuscitation and rewarming by extracorporeal circulation. Intensive care medicine 1990;16:69-72.

66. Lexow K. Severe accidental hypothermia: survival after 6 hours 30 minutes of cardiopulmonary resuscitation. Arctic medical research 1991;50 Suppl 6:112-4.

67. Vretenar DF, Urschel JD, Parrott JC, Unruh HW. Cardiopulmonary bypass resuscitation for accidental hypothermia. The Annals of thoracic surgery 1994;58:895-8.

68. Brugger H, Durrer B, Adler-Kastner L. On-site triage of avalanche victims with asystole by the emergency doctor. Resuscitation 1996;31:11-6.

69. Wada T, Gando S, Mizugaki A, et al. Coagulofibrinolytic changes in patients with disseminated intravascular coagulation associated with post-cardiac arrest syndrome-- 
fibrinolytic shutdown and insufficient activation of fibrinolysis lead to organ dysfunction. Thrombosis research 2013;132:e64-9.

70. Kim J, Kim K, Lee JH, et al. Prognostic implication of initial coagulopathy in out-ofhospital cardiac arrest. Resuscitation 2013;84:48-53. 
VIII. Annexes.

Annexe 1. ${ }^{2}$

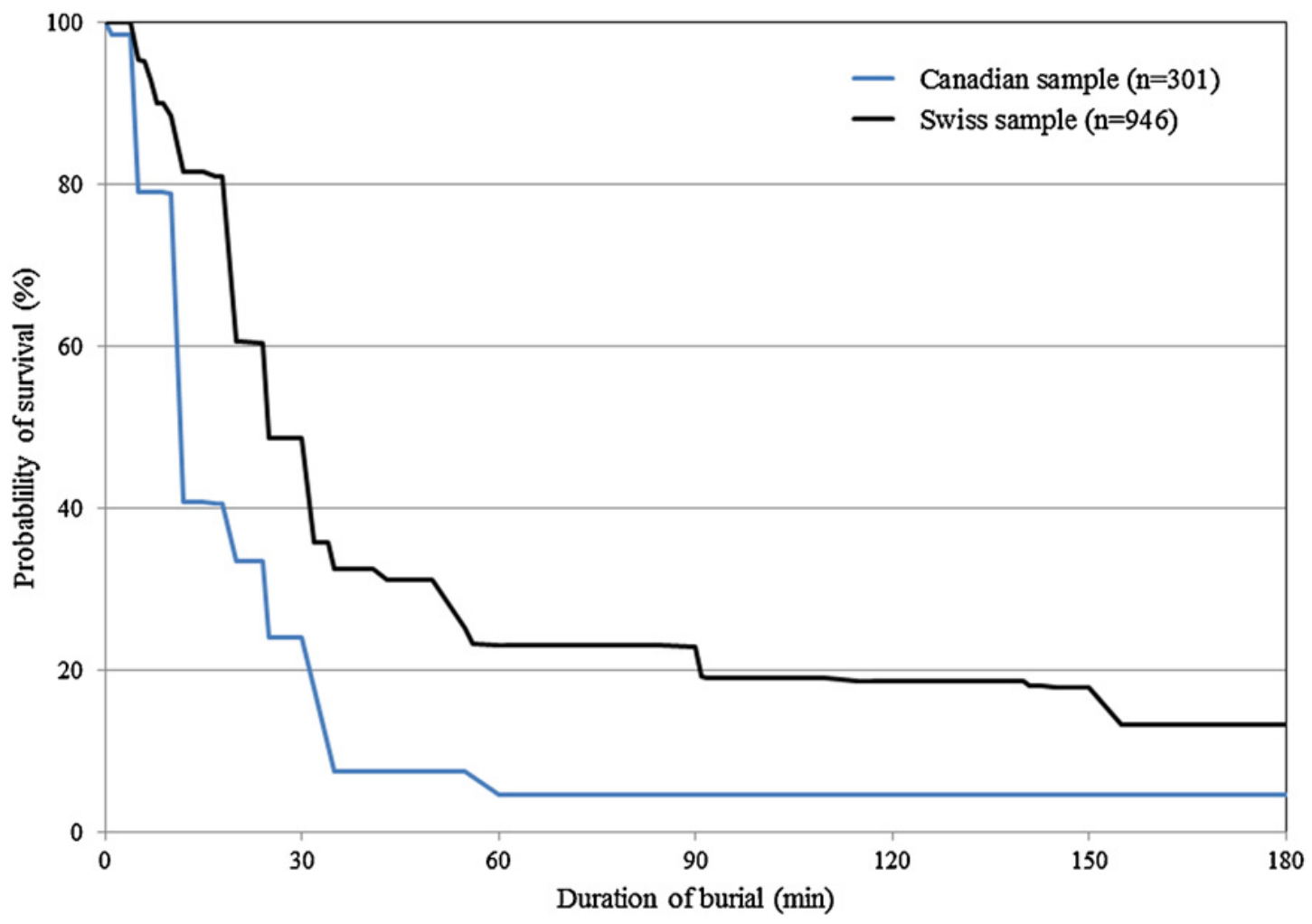


Annexe 2.

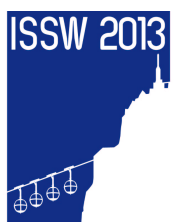

GRENOBLE CHAMONIX MONT-BLANC
Full neurological Recovery of two avalanche victims from prolonged burial and hypothermia cardiac arrest after extracorporeal rewarming

Boué $\mathrm{Y}^{1}$, Blancher $\mathrm{M}^{2}$, Torres $\mathrm{JP}^{2}$, Brun $\mathrm{J}^{1}$, Broux $\mathrm{C}^{1}$, Bouzat $\mathrm{P}^{1}$, Briot $\mathrm{R}^{2}$, Payen $\mathrm{JF}^{1}$, Danel V2

Pôle Anesthésie-Réanimation, CHU GRENOBLE ${ }^{1}$

Pôle Urgences-SAMU-SMUR, CHU GRENOBLE ${ }^{2}$

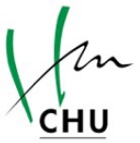

CHU

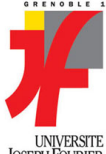

Objective.

To describe the successful neurological recovery from severe accidental hypothermia with cardiac arrest despite the longest reported duration of snow burial and cardiopulmonar resuscitation.

\section{Patient and Intervention.}

Case 1:

A 17 year-old man avalanche victim experienced a 6 hours snow burial in the French Alps (Valmeinier, Savoie) on march 11th 2009. He suffered from profound severe hypothermia and his core body temperature was $21,1^{\circ} \mathrm{C}$. He was unconscious and had an hemodynamic instability (Heart rate $=27 / \mathrm{min}$ and Systolic blood pressure $=55 \mathrm{mmHg}$ ). He presented patent airway and no signs of trauma. After endotracheal intubation and mechanical ventilation (fig 1 ), he was transferred to emergency room of regional level I traumaCase 2 :

centre (Grenoble, France). A cardiac arrest occured afterThe Extra Corporeal Life Support provides Rewarming and Organ Blood flow case report is about a 41 years-old man avalanche hospital arrival in emergency room. Cardiopulmonarvictim. He underwent 7 hours of snow burial on february resuscitation was continued for $\mathbf{2 0}$ min until veno-arterial 2012 in the French Alps (Grand Som, Isère)(fig 3). He extracorporeal membrane oxygenation (ECMO) (fig 2).presented severe hypothermia (core body temperature = After 4 days spent in intensive care unit, he showed a full $23,3^{\circ} \mathrm{C}$ ). He was unconscious without airway obstruction or physical and mental recovery

Figure 1 : Prehospital treatment

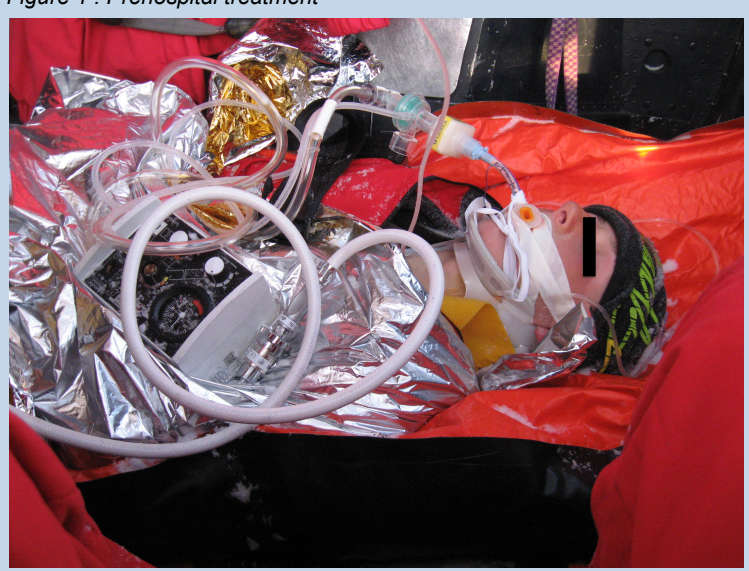
severe trauma at presentation. During extrication, a rescue collapse occured complicated of cardiac arrest. Cardiopulmonar resuscitation was continued for 50 min until ECMO which was begun in Grenoble Emergency Room. After 4 days in intensive care unit, he also had ful neurological recovery.

Figure 3 :

patient's multifunction sport watch-transmitter chest belt recorded dataset

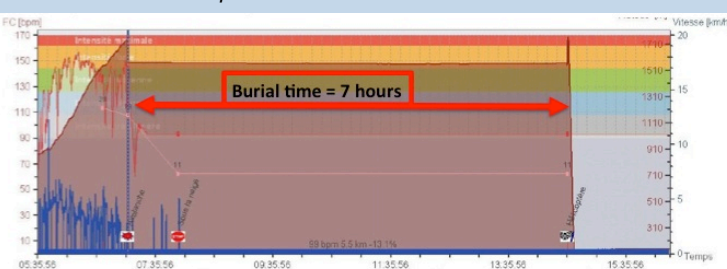

Blue curve : speed

Pink curve : Chest body temperature

Bright Red curve : Heart rate

Dark red curve : altitude

Conclusion.

$>$ Survival probability decreases quickly in relation to the time burried under the snow with a survival rate of $\mathbf{7 \%}$ at $130 \mathrm{~min}^{1}$. This report shows that survival is possible despite a very long time of burial.

$>$ According to a recent article ${ }^{2}$, time to extrication of 7 hours should represents the longest reported duration under avalanche leading to survival with full neurological recovery despite cardiac arrest. Nonetheless, this two patients showed vital signs before cardiac arrest which represents good prognostic factor.

$>$ Rescue teams should carry on the search for avalanche victims, even several hours after avalanche trigger.

$>$ Moreover, with no evidence of trauma or asphyxia, hypothermia cardiac arrest represents a specific condition for which successful neurologic recovery is feasible despite prolonged cardiopulmonary resuscitation ${ }^{3,4,5,6}$. In this specific condition, Rescue teams should pursue cardiopulmonary resuscitation until hospital in order to perform ECMO and rewarming.

References.

1. Brugger H, Durrer B, Adler-Kastner L, Falk M, Tschirky F. Field management of avalanche victims. Resuscitation. 2001;51:7-15

2. Haegeli P, Falk M, Brugger H, Etter HJ, Boyd J. Comparison of avalanche survival patterns in Canada and Switzerland. Clinical Medical Association Journal. 2011. 19;183(7):789-785

4. Brugger $\mathrm{H}$, Durrer B, Elsensohn F, Paal P, Strapazzon G, Winterberger E, Zafren K, Boyd J. Resuscitation of avalanche victims: Evidence-based guidelines of the international commission 5. Boué Y Lavolaine J, Bouzat P, Matraxia S, Chavanon O, Payen JF. Neurological recovery from profound accidental hypothermia after five hours of cardiopulmonary resuscitation. Critical

6. Strappazon G, Avancini G, Blancher M. Accidental Hypothermia. The new England Journal Medicine. 2013;368(7):681-682 
Annexe $3 .^{35}$

\begin{tabular}{|c|c|c|c|}
\hline Stage & Clinical Symptoms & $\begin{array}{l}\text { Typical Core } \\
\text { Temperature'̄ं }\end{array}$ & Treatment \\
\hline HT I & Conscious, shivering & 35 to $32^{\circ} \mathrm{C}$ & $\begin{array}{l}\text { Warm environment and clothing, warm sweet drinks, and active movement } \\
\text { (if possible) }\end{array}$ \\
\hline HT II & $\begin{array}{l}\text { Impaired consciousness, } \\
\text { not shivering }\end{array}$ & $<32$ to $28^{\circ} \mathrm{C}$ & $\begin{array}{l}\text { Cardiac monitoring, minimal and cautious movements to avoid arrhythmias, } \\
\text { horizontal position and immobilization, full-body insulation, active external } \\
\text { and minimally invasive rewarming techniques (warm environment; chemical, } \\
\text { electrical, or forced-air heating packs or blankets; warm parenteral fluids) }\end{array}$ \\
\hline HT III & $\begin{array}{l}\text { Unconscious, not shivering, } \\
\text { vital signs present }\end{array}$ & $<28$ to $24^{\circ} \mathrm{C}$ & $\begin{array}{l}\text { HT II management plus airway management as required; ECMO or CPB in } \\
\text { cases with cardiac instability that is refractory to medical management }\end{array}$ \\
\hline HT IV & No vital signs & $<24^{\circ} \mathrm{C}$ & $\begin{array}{l}\text { HT II and III management plus CPR and up to three doses of epinephrine (at } \\
\text { an intravenous or intraosseous dose of } 1 \mathrm{mg} \text { ) and defibrillation, with fur- } \\
\text { ther dosing guided by clinical response; rewarming with ECMO or CPB (if } \\
\text { available) or CPR with active external and alternative internal rewarming }\end{array}$ \\
\hline
\end{tabular}

* Hypothermia may be determined clinically on the basis of vital signs with the use of the Swiss staging system. ${ }^{10} \mathrm{CPB}$ denotes cardiopulmonary bypass, CPR cardiopulmonary resuscitation, and ECMO extracorporeal membrane oxygenation.

$\uparrow$ Measurement of body core temperature is helpful but not mandatory. The risk of cardiac arrest increases as the core temperature drops below $32^{\circ} \mathrm{C}$ and increases substantially if the temperature is less than $28^{\circ} \mathrm{C}^{12,13}$ To convert values for temperature to degrees Fahrenheit, multiply by $9 / 5$ and add 32 .

\section{Annexe $4 .^{29}$}

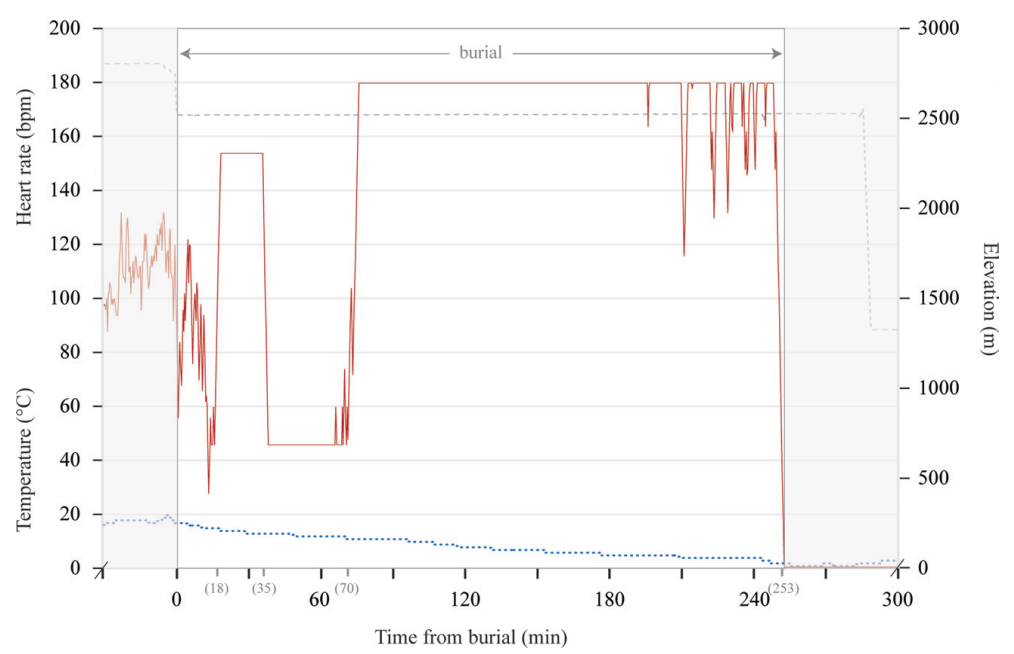

Figure. Heart rate (solid line), cutaneous temperature (dotted line), and elevation (dashed line) in an avalanche victim over the course of 253 minutes of complete avalanche burial. Times of marked changes in cardiac rhythms are given in parentheses (see text). 
Annexe $5 .^{23}$

H. Brugger et al. / Resuscitation 58 (2003) 81-88

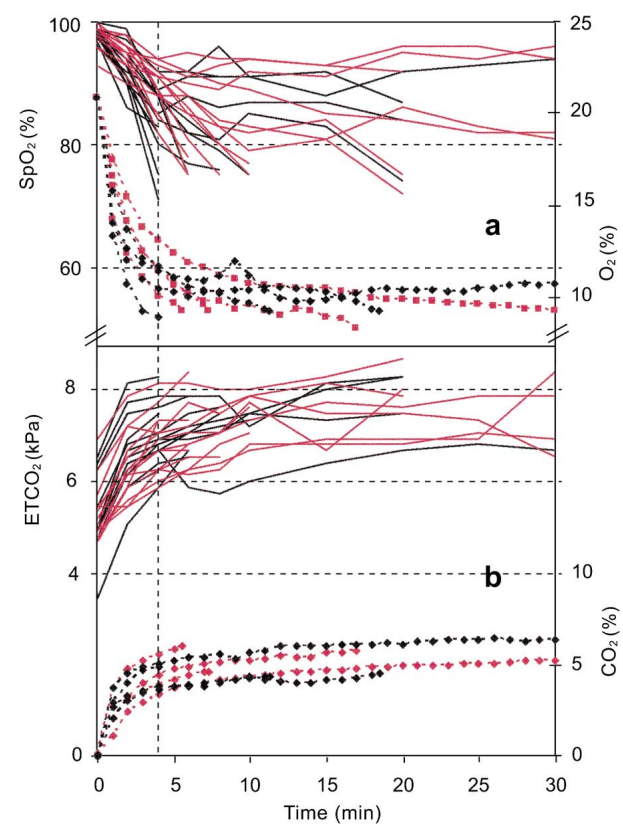
Fig. 1. Curves of individual respiratory parameters in persons breathing into an artificial air pocket in relation to time (min; $n=28)$. (Panel a)
Peripheral $\mathrm{O}_{2}$ saturation ( $\mathrm{Spp}_{2} \%$ ) on the left $y$-axis (continuous line) and $\mathrm{O}_{2}$ concentration (\%) in the air pocket on the right $y$-axis (dotted line). (Panel b) End-idal p $\mathrm{CO}_{2}\left(\mathrm{LTCO}_{2} \mathrm{KPa}\right.$ ) on the left $y$-axis (continuous line) and $\mathrm{CO}_{2}$ concentration (\%) in the air pocket on the right $y$-axis (dotte

Annexe 6.32

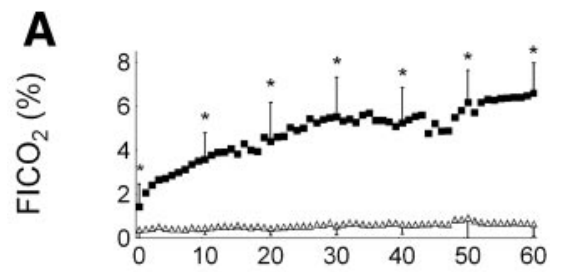

B
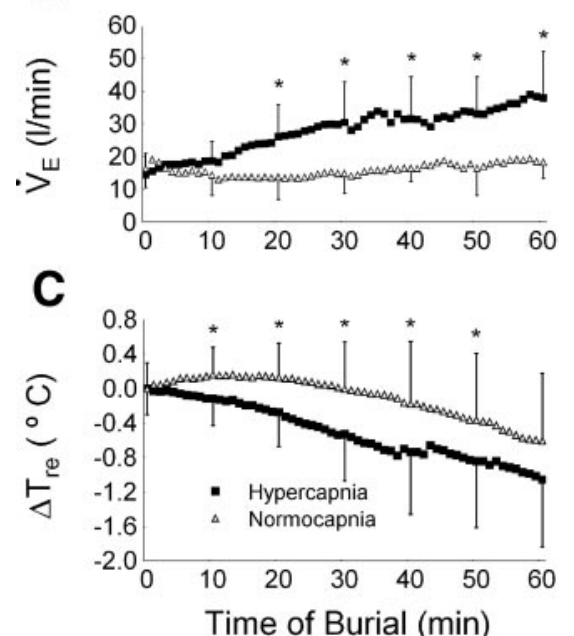

Fig. 4. Mean fraction of inspired carbon dioxide $\left(\mathrm{FI}_{\mathrm{CO}_{2}} ; A\right)$, $\dot{\mathrm{VE}}(B)$, and rectal core body temperature $\left(\mathrm{T}_{\mathrm{re}} ; C\right)$ during burial in dense snow for up to $60 \mathrm{~min}$ during the hypercapnic and normocapnic studies $(n=12)$. Five of the subjects in the hypercapnic study did not complete the full $60 \mathrm{~min}$ of burial (studies terminated at $26,30,35,38$, and $42 \mathrm{~min}$ ). $\mathrm{T}_{\mathrm{re}}$ data are presented as difference from values at time 0 of burial $\left(\Delta \mathrm{T}_{\mathrm{re}}\right)$. Values are means $\pm \mathrm{SD}$. $*$ Significant difference between the hypercapnic and the normocapnic study $(P<0.05)$. 
Annexe $7 .^{32}$

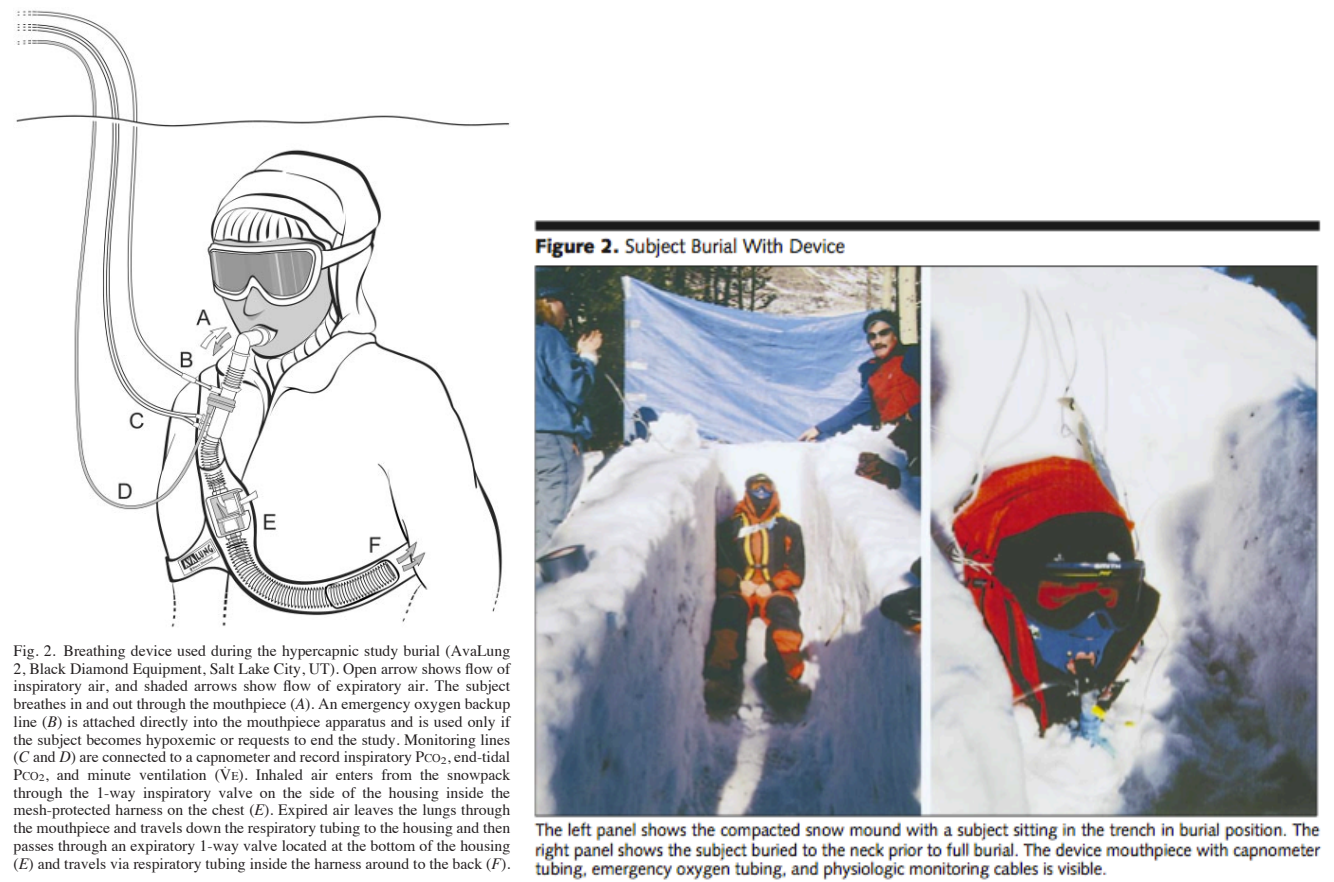

Annexe $8 .^{24}$

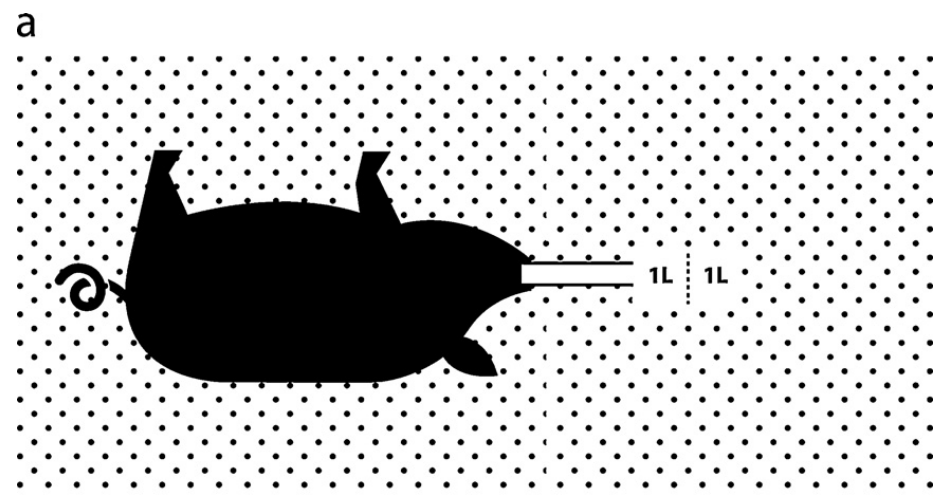

b

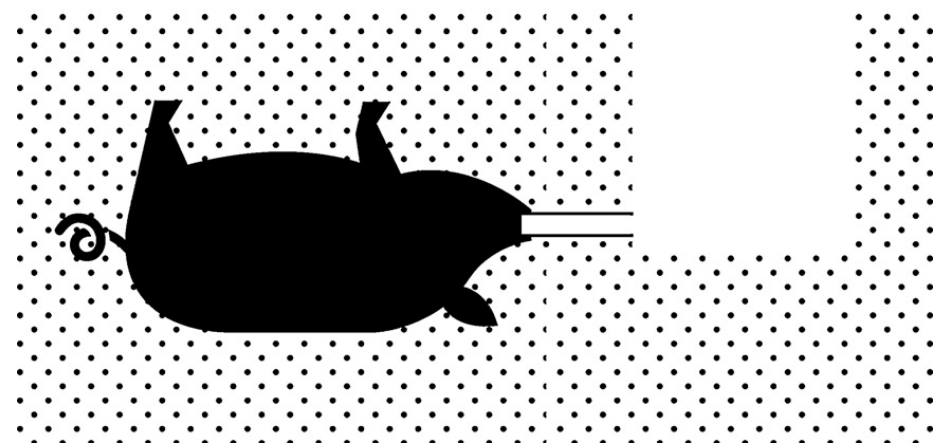

Fig. 1. Experimental avalanche burial with anaesthetised, intubated piglets breathing (a) into an air pocket of snow of $1 \mathrm{~L}$ or $2 \mathrm{~L}$ volume (air pocket group) or (b) environmental air (ambient air group). The piglets were connected with an endotracheal tube either to the air pocket or to the ambient air space and were separated from the space by an airtight aluminium disc (grey). 
Annexe 9.24
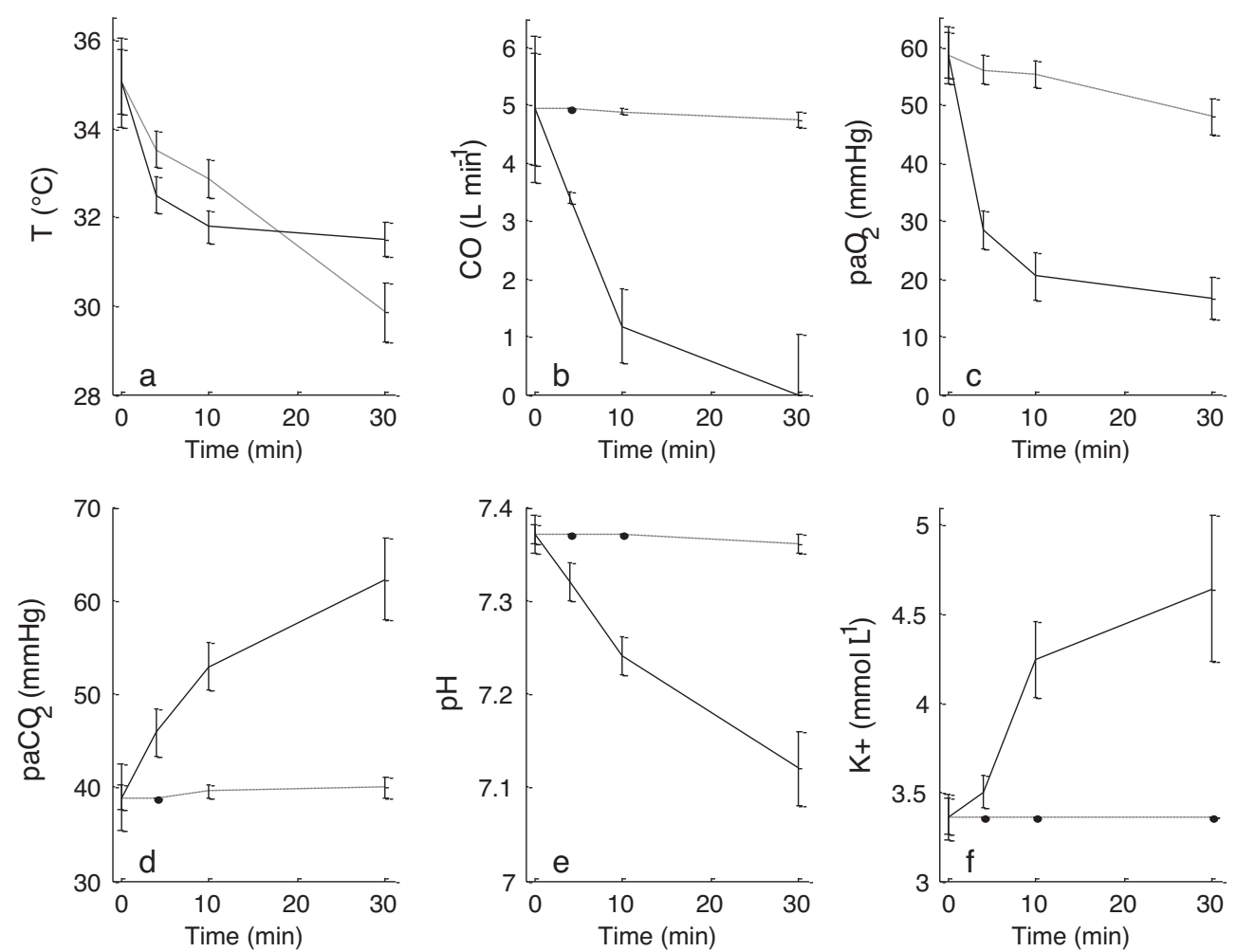

Fig. 2. Mean \pm standard error (SEM) at 0 (baseline), and mean \pm SEM for baseline corrected values at 4,10 and 30 min for the air pocket ( $n=5$, solid line) and ambient air group ( $n=3$, dashed line) for core body temperature (a, ANOVA for repeated measures group effect $P=0.782$, time effect $P<0.001$, interaction effect $P<0.001$ ), cardiac output (b, gre dioxide partial pressure (d, group $P=0.007$, time $P=0.009$, interaction effect $P=0.019$ ), arterial $\mathrm{pH}$ (e, group $P=0.002$, time $P=0.001$, interaction effect $P=0.002$ ) and serum
potassium (f, group $P=0.042$, time $P=0.021$, interaction effect $P=0.021$ ).

\section{Annexe $10.56,59$}

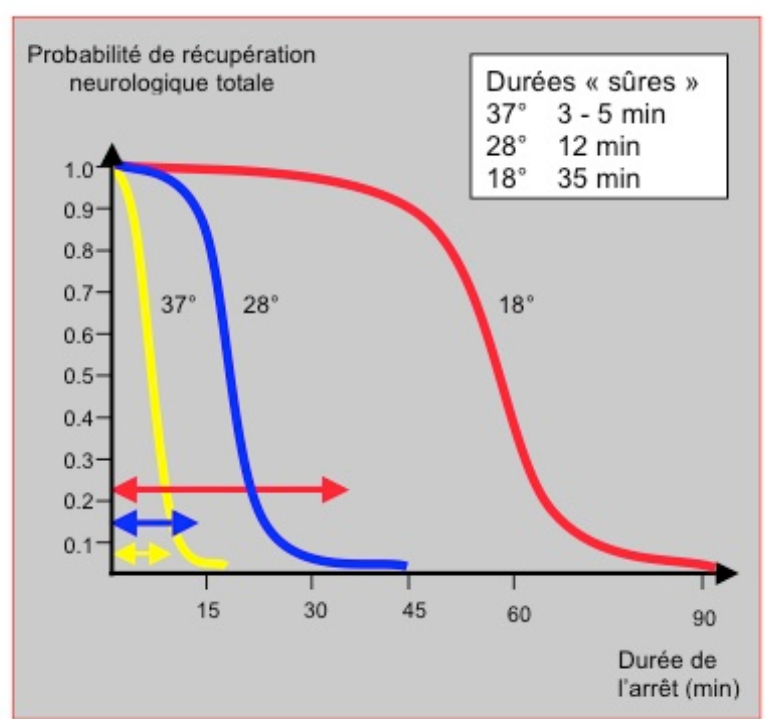

\section{Annexe 11.63}

\footnotetext{
CPC 1 Good cerebral performance (normal life). Conscious; alert, able to work. May have minor neurologic or psychologic deficit (mild dysphagia, nonincapacitating hemiparesis, or minor cranial nerve abnormalities).

CPC 2 Moderate cerebral disability (disabled but independent). Conscious; sufficient cerebral function for independent activities of daily life. Able to work in sheltered environment. May have hemiplegia, seizures, ataxia, dysarthria, dysphasia, or permanent memory or mental changes.

CPC 3 Severe cerebral disability (conscious but disabled and dependent). Conscious; dependent on others for daily support because of impaired brain function. Limited cognition. Ranges from ambulatory state to severe dementia or paralysis.

CPC 4 Coma/vegetative state (unconscious). Unconscious, unaware of surroundings, no cognition. No verbal or psychologic interaction with environment.

CPC 5 Brain death. Certified brain dead or dead by traditional criteria.
} 


\section{Survival after avalanche-induced cardiac arrest}

(Article actuellement soumis au journal Resuscitation)

\section{Abstract (250 words)}

Aim: Criteria to prolong resuscitation after cardiac arrest (CA) induced by avalanche burial are critical due to the role of associated profound hypothermia. We sought parameters associated with survival in a cohort of victims of complete avalanche burial.

Methods: Retrospective observational study from 1994 to 2013 in the Northern French Alps with on-scene CA patients after avalanche burial. Criteria associated with survival at the intensive care unit (ICU) discharge were collected on the scene and at the admission to Level1 trauma center. Neurological outcome was assessed at 3 months using cerebral performance category.

Results: Forty-eight patients were studied. They were buried for a median time of $43 \mathrm{~min}$ (25$76 \mathrm{~min} ; 25-75^{\text {th }}$ percentiles $)$ and had a pre-hospital body core temperature of $28.0^{\circ} \mathrm{C}(26.0$ 30.7). Eighteen patients had pre-hospital return of spontaneous circulation and 30 had refractory CA. Twenty-one patients had extracorporeal life support for rewarming. Eight patients survived at ICU discharge and 3 patients had favorable neurological outcome at 3 months. Pre-hospital parameters associated with survival were the presence of air pocket and a rescue collapse. On admission, survivors had lower serum potassium concentration than non-survivors: $3.2 \mathrm{mmol} / \mathrm{L}(2.7-4.0)$ versus $5.6 \mathrm{mmol} / \mathrm{L}(4.2-8.0)$, respectively $(\mathrm{P}<0.01)$. They also had normal prothrombin and activated partial thromboplastin compared to non-survivors. Conclusions: Our findings indicate that survival after avalanche burial and on-scene CA is rarely associated with favourable neurological outcome. Among criteria associated with survival, normal blood coagulation on admission should deserve further confirmation.

Key words: cardiac arrest, avalanche, burial, hypothermia 
Introduction

In North America and Europe, 150 patients are killed by avalanche burial every year, which corresponds to a mortality rate of $70 \%$ following complete burial. ${ }^{2}$ There are three main causes of cardiac arrest (CA) following avalanche burial: asphyxia, severe trauma and/or profound hypothermia. ${ }^{3,13}$ Asphyxia is the leading cause of death and poor neurological outcome. ${ }^{3-5,13}$ Death or unfavorable outcome after severe trauma is not uncommon as well. ${ }^{3-5}$ CA induced by isolated profound hypothermia is less frequent ${ }^{3,13}$ but is associated with a better neurological recovery regardless the duration of burial..$^{7-9,15}$

In clinical practice, the exact cause of CA may be unclear because CA and profound hypothermia can be associated on the scene of avalanche burial. This situation may lead to prolonged resuscitation in the emergency room (ER), including extracorporeal life support (ECLS) rewarming, and raises inevitably the question of the futility of such treatments for all patients. In this way, international guidelines recommend the termination of cardiopulmonary resuscitation (CPR) in buried patients with asystole if they are lethally injured or completely frozen, if the airway is packed with snow and the burial duration exceeds 35 min. ${ }^{13}$ Serum potassium concentration higher than $12 \mathrm{mmol} / \mathrm{L}$ on hospital admission is also another criterion used to terminate CPR. Because medical decision may be difficult to take in the ER context in buried patients with on-scene CA, we conducted a retrospective analysis over the last 20 years in the Northern French Alps to describe factors associated with outcome. 
Patients and methods

We retrospectively analyzed all consecutive patients admitted to ER following avalanche burial and on-scene CA during the 20 last years (1994-2013). Pre-hospital triage and resuscitation of avalanche victims were conducted according to the international guidelines and performed by emergency physicians (Fig. 1). On admission, the decision of ECLS rewarming was made according to the results of bedside imaging modalities, i.e., chest and pelvic radiography, abdominal and thoracic ultrasonography, serum potassium measurements and body core temperature. Blood samples were obtained from femoral arterial or venous accesses. Patients with severe trauma or with a body temperature higher than $32^{\circ} \mathrm{C}$ were not eligible for ECLS. ${ }^{9,13,35,36}$ A serum potassium concentration exceeding $10 \mathrm{mmol} / \mathrm{L}$ on admission was another criterion to refute ECLS. ${ }^{36}$

Data were extracted from the registry of the Northern French Alps Trauma System, which prospectively collected data using the Utstein-style for data reporting after major trauma. ${ }^{62}$ This registry was approved and recorded by the French National Committee for protection of personal and public liberties. This committee approved access to anonymous data on relevant patients in the trauma registry.

The collection of data included the duration of burial, body core temperature, treatments on admission, and biological data. Also were noted the presence of airway obstruction, the notion of air pocket before extraction, a rescue collapse during the body extraction, evidence of trauma, the initial cardiac rhythm, a return of spontaneous circulation (ROSC), and a transport under chest compressions. Survival was reported at the discharge from the intensive care unit (ICU). Neurological outcome was assessed using cerebral performance category (CPC) score at 3 months. ${ }^{64}$ A good neurological outcome was defined as a CPC score of 1 or 2.

Data were expressed as median and range $\left(25-75^{\text {th }}\right.$ percentiles $)$. Categorical variables were compared with Chi2 test, and continuous variables were compared using the non- 
parametric Mann-Witney test (StatView SE program, SAS Institute, Cary, NC). Due to the limited number of the study population, we conducted univariate analysis only. Statistical significance was declared when $P<0.05$. 
Results

Over 70 patients admitted to ER following avalanche burial during the study period, 22 patients had no on-scene CA. Patients considered for analysis were 45 patients referred to the Grenoble University Hospital and 3 patients to the Annecy General Hospital (Fig. 2). Prehospital characteristics of the studied patients are shown in Table 1. Typical patient is young, male, and buried for $45 \mathrm{~min}$. The median duration of CPR was $90 \mathrm{~min}$. Eight patients had vital signs preceding CA such as spontaneous breathing, carotid pulse, electric cardiac activity or signs of consciousness at the initial presentation. Thirty patients were transferred to ER with no ROSC during the pre-hospital management.

Characteristics of the study population at the admission to ER are shown in Table 2. Although patients had marked metabolic acidosis, only 4 patients had serum potassium concentration higher than $12 \mathrm{mmol} / \mathrm{L}$. There were 21 patients eligible for ECLS rewarming: 2 with pre-hospital ROSC due to hemodynamic instability on admission, and 19 patients with refractory CA (Fig. 2). CPR was terminated for 11 patients with refractory CA because of a serum potassium concentration exceeding $10 \mathrm{mmol} / \mathrm{L}$ ( 9 patients), a severe chest trauma (1 patient) or a body core temperature higher than $32^{\circ} \mathrm{C}(1$ patient $)$.

Among the remaining 37 patients who underwent resuscitation, 29 patients deceased mainly from brain death (11 patients) and multi-organ failure ( 8 patients). Table 3 shows the univariate analysis between non-survivors ( $\mathrm{n}=29$ patients) and survivors ( $\mathrm{n}=8$ patients). Survivors had a smaller duration of $\mathrm{CPR}$, lower arterial $\mathrm{pH}$, and no coagulation disturbances on admission by comparison with non-survivors. The highest serum potassium concentration was $4.2 \mathrm{mmol} / \mathrm{L}$ in survivors versus $10 \mathrm{mmol} / 1$ in non-survivors. No differences were found between the 2 groups regarding the duration of burial and pre-hospital body core temperature.

Eight patients were alive at the ICU discharge. A CPC score of 1 was found for 3 patients. The remaining patients had a CPC score of 3 (1 patient) and 4 (4 patients). The 3 patients with good neurological outcome had all been treated with ECLS due to refractory CA 
and presented on-scene signs of life or were buried in an air pocket before extraction. They even had a longer duration of burial time compared to non-survivor patients treated with ECLS: $390 \mathrm{~min}(375-405 \mathrm{~min})$ vs. $50 \mathrm{~min}(27-75 \mathrm{~min})$, respectively $(\mathrm{P}=0.03)$. Two of them had a very prolonged duration of avalanche burial, i.e., 7 and 6 hours. 
Discussion

Our series is the largest of avalanche victims with on-scene CA who were admitted to ER. ${ }^{11,18,19,27}$ Survival was found in 8 out of 48 patients only, and 3 patients had favorable neurological outcome at 3 months after the insult. The absence of coagulation disorders and a normal serum potassium concentration on admission were associated with survival, in addition with on-scene signs of life and air pocket.

The survival rate is $17 \%$ ( $8 / 48$ patients) in this study, in line with other series of avalanche victims. ${ }^{11,19}$ Mortality rate in this situation is much higher than mortality after isolated profound hypothermia. ${ }^{15,17-21}$ The role of asphyxia after complete avalanche burial may account for this difference in mortality.

The presence of vital signs on the scene was associated with a good neurological outcome, i.e., CPC score 1 at 3 months, although these 3 patients with CPC 1 had rescue collapse during their initial presentation. Rescue collapse is defined by the occurrence of CA related to the extrication or transfer of patient in profound hypothermia. This phenomenon is attributed to a circulatory collapse due to hypovolemia, cardiac arrhythmias triggered by transfer of the patient, and further cooling. ${ }^{16,35}$ However, rescue collapse was also found in 3 non-survivors, indicating that rescue collapse do not guarantee a favorable neurological outcome. ${ }^{29}$ The presence of air pocket was associated with survival in our cohort, as found elsewhere. ${ }^{2,25,32,68}$ Hence, the presence of vital signs preceding CA and air pocket were indicators of the nature of CA, possibly induced by a profound hypothermia.

We found that the duration of burial time was not associated with outcome. According to the Brugger curve, ${ }^{2}$ the etiology of CA after several hours of complete burial could be related to profound hypothermia. This condition represents a few proportions of avalanche victims with best chance to recover favorably. ${ }^{7-9,17}$ In our cohort, two survivors presented exceptional burial time of 7 hours and 6 hours under avalanche, that illustrates the importance to carry on search for avalanche victims. 
We found that the serum potassium concentration on admission was significantly associated with mortality as shown previoulsy. ${ }^{11,27,34}$ In our cohort, the highest serum potassium concentration was $4.2 \mathrm{mmol} / \mathrm{L}$ in survivors. Considering the overall population, only 4 patients out of 48 presented serum potassium concentration higher than $12 \mathrm{mmol} / \mathrm{L}$ on hospital admission. In a retrospective case-control study of 32 avalanche victims, serum potassium concentration was $4.2 \pm 4.9 \mathrm{mmol} / \mathrm{L}(3.1-6.4 \mathrm{mmol} / \mathrm{L})$ in survivors versus $9.9 \pm 4.9$ $\mathrm{mmol} / \mathrm{L} \quad(2.0-18.0 \mathrm{mmol} / \mathrm{L})$ in non-survivors. ${ }^{11}$ International guidelines recommend considering ECLS when serum potassium concentration is lower than $10-12 \mathrm{mmol} / \mathrm{L} .{ }^{9,13,35,36}$ Collectively, these findings suggest that the threshold for serum potassium concentration should be revisited toward lower values.

Our non-survivors had coagulation disturbances on admission as assessed with simple tests such as prothrombin and activated partial thromboplastin ratios. There are no previous data that documented such disturbances after complete avalanche burial. Moreover, there was no overlap in the prothrombin values between survivors and non-survivors. Markers of disseminated intravascular coagulation were recently associated with multi-organ failure in 52 patients after $\mathrm{CA}^{69}$, and coagulopathy was associated with mortality and unfavorable neurological outcome in 250 patients with extra-hospital CA. ${ }^{70}$ Exacerbated activation of coagulation by post-cardiac arrest syndrome might account for the early mortality in our cohort. Global exploration of hemostasis using thromboelastography or thromboelastometry would be of value in this population. Nevertheless, bedside assessment of coagulation is easily accessible on admission that should raise more attention of these tests in the medical decision process of prolonged resuscitation of these patients.

Our study has several limitations. Firstly, we performed a retrospective analysis with potential bias due to the evolution of medical standard of care during the 20 -year study period. A regional avalanche register in the Northern French Alps Trauma System is ongoing to collect data regarding avalanche victims prospectively. Secondly, we did not perform 
multivariate analysis to determine independent predictors of survival in our cohort. Our small number of survivors ( $\mathrm{n}=8$ patients) could not allow to perform such analysis. 
Conclusion

Cardiac arrest after complete avalanche burial is a dramatic condition resulting to a high mortality rate. In a series of $48 \mathrm{CA}$ patients admitted to level-I emergency room in the Northern French Alps, only 8 survived at the hospital discharge, and 3 had favorable neurological outcome 3 months after the insult. Collecting criteria is essential to help medical decision on whether to prolong resuscitation at the admission of these patients. 
References

1. Brugger H, Durrer B, Adler-Kastner L, Falk M, Tschirky F. Field management of avalanche victims. Resuscitation 2001;51:7-15.

2. Brugger H, Durrer B, Elsensohn F, et al. Resuscitation of avalanche victims: Evidence based guidelines of the international commission for mountain emergency medicine (ICAR MEDCOM): intended for physicians and other advanced life support personnel. Resuscitation 2013;84:539-46.

3. Boyd J, Haegeli P, Abu-Laban RB, Shuster M, Butt JC. Patterns of death among avalanche fatalities: a 21-year review. CMAJ 2009;180:507-12.

4. Hohlrieder M, Brugger H, Schubert HM, Pavlic M, Ellerton J, Mair P. Pattern and severity of injury in avalanche victims. High Alt Med Biol 2007;8:56-61.

5. McIntosh SE, Grissom CK, Olivares CR, Kim HS, Tremper B. Cause of death in avalanche fatalities. Wilderness Environ Med 2007;18:293-7.

6. Boue Y, Lavolaine J, Bouzat P, Matraxia S, Chavanon O, Payen JF. Neurologic recovery from profound accidental hypothermia after 5 hours of cardiopulmonary resuscitation. Crit Care Med 2014;42:e167-70.

7. Boyd J, Brugger H, Shuster M. Prognostic factors in avalanche resuscitation: a systematic review. Resuscitation 2010;81:645-52.

8. Oberhammer R, Beikircher W, Hormann C, et al. Full recovery of an avalanche victim with profound hypothermia and prolonged cardiac arrest treated by extracorporeal rewarming. Resuscitation 2008;76:474-80.

9. Gilbert M, Busund R, Skagseth A, Nilsen PA, Solbo JP. Resuscitation from accidental hypothermia of 13.7 degrees C with circulatory arrest. Lancet 2000;355:375-6.

10. Brown DJ, Brugger H, Boyd J, Paal P. Accidental hypothermia. New Engl J Med 2012;367:1930-8. 
11. Vanden Hoek TL, Morrison LJ, Shuster M, et al. Part 12: cardiac arrest in special situations: 2010 American Heart Association Guidelines for Cardiopulmonary Resuscitation and Emergency Cardiovascular Care. Circulation 2010;122:S829-61.

12. Dick WF, Baskett PJ. Recommendations for uniform reporting of data following major trauma--the Utstein style. A report of a working party of the International Trauma Anaesthesia and Critical Care Society (ITACCS). Resuscitation 1999;42:81100.

13. Phelps R, Dumas F, Maynard C, Silver J, Rea T. Cerebral Performance Category and long-term prognosis following out-of-hospital cardiac arrest. Crit Care Med $2013 ; 41: 1252-7$.

14. Farstad M, Andersen KS, Koller ME, Grong K, Segadal L, Husby P. Rewarming from accidental hypothermia by extracorporeal circulation. A retrospective study. Eur J Cardiothorac Surg 2001;20:58-64.

15. Locher $\mathrm{T}$, Walpoth BH. Differential diagnosis of circulatory failure in hypothermic avalanche victims: retrospective analysis of 32 avalanche accidents. Schweiz Rundsch Med Prax 1996;85:1275-82.

16. Mair P, Kornberger E, Furtwaengler W, Balogh D, Antretter H. Prognostic markers in patients with severe accidental hypothermia and cardiocirculatory arrest. Resuscitation $1994 ; 27: 47-54$

17. Ruttmann E, Weissenbacher A, Ulmer H, et al. Prolonged extracorporeal membrane oxygenation-assisted support provides improved survival in hypothermic patients with cardiocirculatory arrest. J Thorac Cardiovasc Surg 2007;134:594-600.

18. Silfvast T, Pettila V. Outcome from severe accidental hypothermia in Southern Finland--a 10-year review. Resuscitation 2003;59:285-90.

19. Walpoth BH, Walpoth-Aslan BN, Mattle HP, et al. Outcome of survivors of accidental deep hypothermia and circulatory arrest treated with extracorporeal blood warming. New Engl J Med 1997;337:1500-5. 
20. Schober A, Sterz F, Handler C, et al. Cardiac arrest due to accidental hypothermia-a 20 year review of a rare condition in an urban area. Resuscitation 2014;doi10.1016/j.resuscitation.2014.01.027.

21. Danzl DF, Pozos RS, Auerbach PS, et al. Multicenter hypothermia survey. Ann Emerg Med 1987;16:1042-55.

22. Strapazzon G, Beikircher W, Procter E, Brugger H. Electrical heart activity recorded during prolonged avalanche burial. Circulation 2012;125:646-7.

23. Brugger H, Durrer B, Adler-Kastner L. On-site triage of avalanche victims with asystole by the emergency doctor. Resuscitation 1996;31:11-6.

24. Falk M, Brugger H, Adler-Kastner L. Avalanche survival chances. Nature 1994;368:21.

25. Grissom CK, Radwin MI, Harmston CH, Hirshberg EL, Crowley TJ. Respiration during snow burial using an artificial air pocket. JAMA 2000;283:2266-71.

26. Schaller MD, Fischer AP, Perret CH. Hyperkalemia. A prognostic factor during acute severe hypothermia. JAMA 1990;264:1842-5.

27. Wada T, Gando S, Mizugaki A, et al. Coagulofibrinolytic changes in patients with disseminated intravascular coagulation associated with post-cardiac arrest syndrome-fibrinolytic shutdown and insufficient activation of fibrinolysis lead to organ dysfunction. Thromb Res 2013;132:e64-9.

28. Kim J, Kim K, Lee JH, et al. Prognostic implication of initial coagulopathy in out-ofhospital cardiac arrest. Resuscitation 2013;84:48-53. 
Table 1. Pre-hospital characteristics of the 48 studied patients.

\begin{tabular}{|c|c|}
\hline Variables & Values \\
\hline Age (years) & $33(22-41)$ \\
\hline Male gender (number) & 38 \\
\hline Prehospital body core temperature $\left({ }^{\circ} \mathrm{C}\right)$ & $28.0(26.0-30.7)$ \\
\hline Burial time (min) & $43(25-76)$ \\
\hline Maximum duration of no flow (min) & $35(20-65)$ \\
\hline Duration of low flow (min) & $90(18-127)$ \\
\hline \multicolumn{2}{|l|}{ Prehospital cardiac rhythm (number): } \\
\hline Asystole & 38 \\
\hline Ventricular fibrillation & 2 \\
\hline Pulseless electrical activity & 8 \\
\hline Rescue collapse (number) & 6 \\
\hline Return of spontaneous circulation (number) & 18 \\
\hline Transport under CPR (number) & 30 \\
\hline Vital signs preceding CA (number) & 8 \\
\hline Prehospital trauma signs (number) & 8 \\
\hline Prehospital airway obstruction (number) & 2 \\
\hline Air pocket (number) & 5 \\
\hline
\end{tabular}

Values are expressed as median and interquartile range. CPR, cardiopulmonary resuscitation; CA, cardiac arrest 
Table 2. Biological data on admission to the emergency room of the 48 studied patients.

\begin{tabular}{lc} 
Variables & Values \\
\hline Serum potassium $(\mathrm{mmol} / \mathrm{L})$ & $5.6(4.0-8.6)$ \\
Serum sodium $(\mathrm{mmol} / \mathrm{L})$ & $143(138-147)$ \\
Arterial pH & $6.9(6.6-7.1)$ \\
$\mathrm{PaCO} 2(\mathrm{mmHg})$ & $54.7(36.1-146.6)$ \\
$\mathrm{PaO} 2(\mathrm{mmHg})$ & $343.4(80.8-560.9)$ \\
Serum bicarbonate $(\mathrm{mmol} / \mathrm{L})$ & $9.9(5-13.8)$ \\
Serum lactate $(\mathrm{mmol} / \mathrm{L})$ & $13.2(8.8-15.6)$ \\
Hemoglobin $(\mathrm{g} / \mathrm{L})$ & $143(119-156)$ \\
Platelets $(\mathrm{G} / \mathrm{L})$ & $146(119-192)$ \\
Activated Partial Thromboplastin ratio & $2.42(1.5-3.6)$ \\
Prothrombine ratio $(\%)$ & $41(23-56)$ \\
Serum fibrinogen $(\mathrm{g} / \mathrm{L})$ & $1.3(0.7-1.8)$ \\
Serum creatinine $(\mu \mathrm{mol} / \mathrm{L})$ & $142(116-174)$ \\
Serum glucose $(\mathrm{mmol} / \mathrm{L})$ & $15.1(11.3-18.6)$
\end{tabular}

Values are expressed as median and $25-75^{\text {th }}$ percentiles. 
Table 3. Univariate analysis of the 37 patients who underwent resuscitation, including 29 non-survivors and 8 survivors at discharge from the intensive care unit.

\begin{tabular}{|c|c|c|c|}
\hline Variables & $\begin{array}{l}\text { Non-survivors } \\
\mathrm{N}=29 \text { patients }\end{array}$ & $\begin{array}{c}\text { Survivors } \\
\mathrm{N}=8 \text { patients }\end{array}$ & $\mathrm{P}$ \\
\hline Age (years) & $32(22-43)$ & $37.5(30.5-40.3)$ & 0.77 \\
\hline Male gender & 22 & 7 & 0.48 \\
\hline Prehospital body core temperature $\left({ }^{\circ} \mathrm{C}\right)$ & $28.0(26.8-30.7)$ & $26.5(24.7-28.1)$ & 0.12 \\
\hline Burial time (min) & $35(25-58)$ & $25(20-203)$ & 0.89 \\
\hline Maximum no flow (min) & $35(23-50)$ & $20(0-21)$ & 0.01 \\
\hline Low flow (min) & $95(20-133)$ & $13(7-26)$ & 0.01 \\
\hline \multicolumn{4}{|l|}{ Prehospital cardiac rhythm: } \\
\hline Asystole & 24 & 5 & 0.23 \\
\hline Ventricular fibrillation & 1 & 0 & 0.60 \\
\hline Pulseless electrical activity & 4 & 3 & 0.58 \\
\hline Rescue collapse & 3 & 3 & 0.07 \\
\hline Prehospital signs of life & 4 & 3 & 0.13 \\
\hline Prehospital trauma signs & 5 & 2 & 0.62 \\
\hline Prehospital airway obstruction & 2 & 0 & 0.45 \\
\hline Air pocket & 2 & 3 & 0.06 \\
\hline ECLS & 18 & 3 & 0.38 \\
\hline Serum potassium (mmol/L) & $5.6(4.2-8.0)$ & $3.2(2.7-4.0)$ & 0.001 \\
\hline Serum sodium (mmol/L) & $144(139-147)$ & $137(136-139)$ & 0.003 \\
\hline Arterial $\mathrm{pH}$ & $6.81(6.60-7.00)$ & $7.18(7.13-7.19)$ & 0.01 \\
\hline $\mathrm{PaCO}_{2}(\mathrm{mmHg})$ & $57(38-137)$ & $37(35-54)$ & 0.29 \\
\hline $\mathrm{PaO}_{2}(\mathrm{mmHg})$ & $514(372-654)$ & $133(54-439)$ & 0.01 \\
\hline Bicarbonate (mmol/L) & $9(5-12)$ & $15(10-18)$ & 0.01 \\
\hline Lactate $(\mathrm{mmol} / \mathrm{L})$ & $13.9(10.8-16.3)$ & $9.1(6.9-12.6)$ & 0.07 \\
\hline Hemoglobin (g/L) & $139(116-157)$ & $147(126-154)$ & 0.70 \\
\hline Thrombocyte (Giga/L) & $145(106-188)$ & $160(132-214)$ & 0.27 \\
\hline Activated Partial Thromboplastin ratio & $3.3(1.9-3.7)$ & $1.3(0.9-1.9)$ & 0.01 \\
\hline Prothrombine ratio $(\%)$ & $30(19-51)$ & $64(54-83)$ & 0.01 \\
\hline Fibrinogen $(\mathrm{g} / \mathrm{L})$ & $1.1(0.6-1.7)$ & $1.7(1.6-2.3)$ & 0.04 \\
\hline Creatine kinase (IU/L) & $817(548-1847)$ & $726(579-2253)$ & 0.90 \\
\hline Cardiac Troponine I $(\mu \mathrm{g} / \mathrm{L})$ & $0.31(0.06-0.41)$ & $0.04(0.02-0.17)$ & 0.03 \\
\hline Creatinine $(\mu \mathrm{mol} / \mathrm{L})$ & $144(129.5-182.5)$ & $96(81-133)$ & 0.02 \\
\hline
\end{tabular}

Values are expressed as median (interquartile range). ECLS, ExtraCorporeal Life Support. 
Figure legend

Figure 1. Cardiac arrest management of a buried avalanche victim. CPR, cardiopulmonary resuscitation; ALS, Advanced Life Support; ECG, electrocardiogram; ECLS, Extracorporeal Life Support.

Figure 2. Flowchart of victims of burial avalanche. ECLS, ExtraCorporeal Life Support; ROSC, Return Of Spontaneous Circulation; $\mathrm{K}+$, serum potassium concentration; $\mathrm{T}$, body core temperature. 
Figure 1.

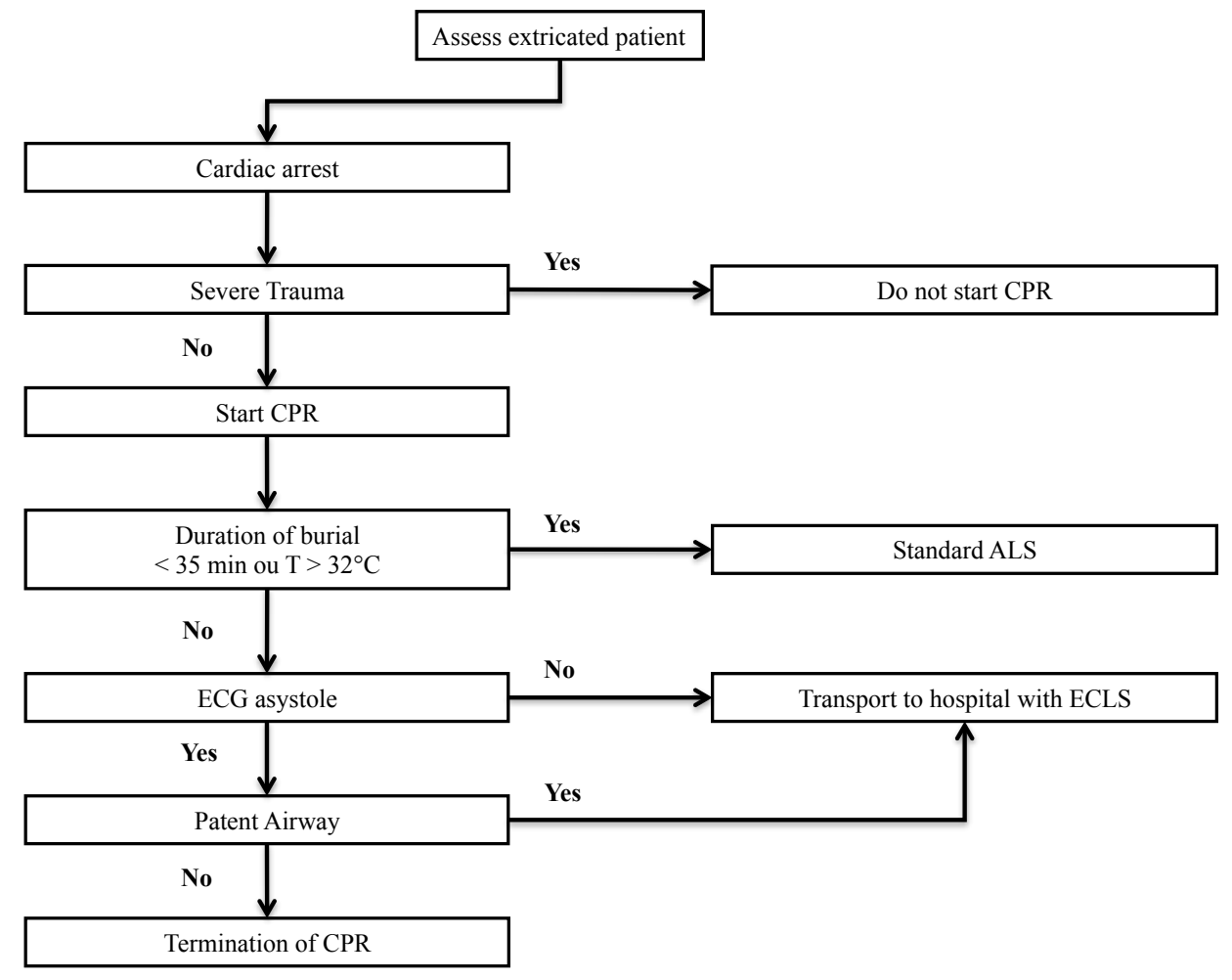


Figure 2.

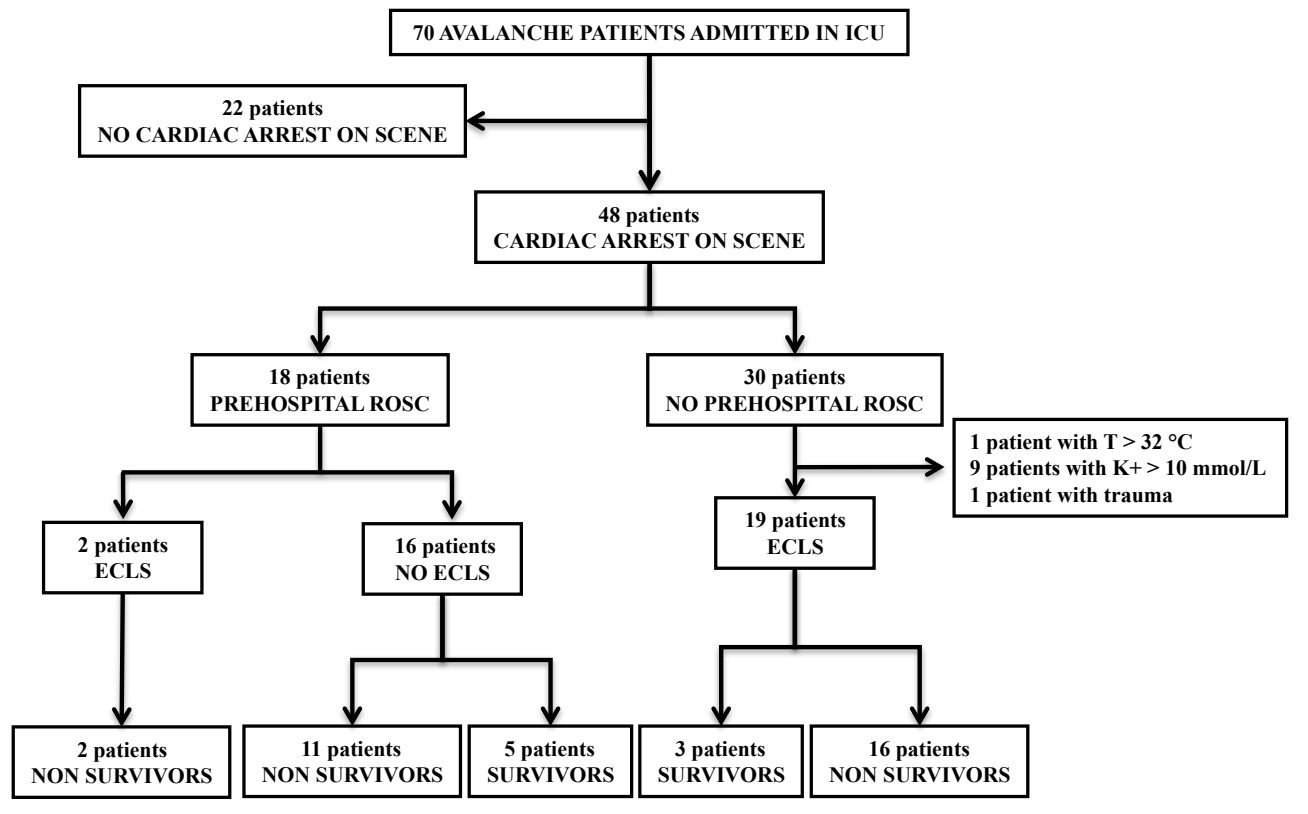




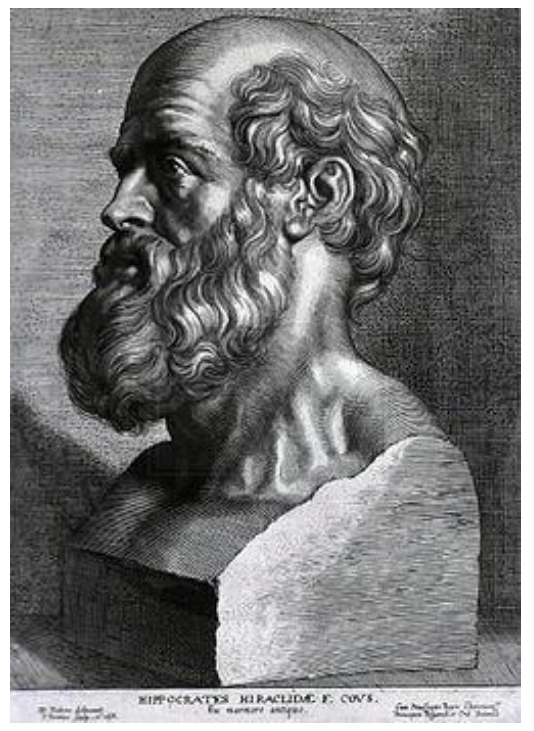

\section{SERMENT D'HIPPOCRATE}

En présence des Maîtres de cette Faculté, de mes chers condisciples et devant l'effigie d'HIPPOCRATE,

Je promets et je jure d'être fidèle aux lois de l'honneur et de la probité dans l'exercice de la Médecine.

Je donnerais mes soins gratuitement à l'indigent et n'exigerai jamais un salaire au dessus de mon travail. Je ne participerai à aucun partage clandestin d'honoraires.

Admis dans l'intimité des maisons, mes yeux n'y verront pas ce qui s'y passe ; ma langue taira les secrets qui me seront confiés et mon état ne servira pas à corrompre les mours, ni à favoriser le crime.

Je ne permettrai pas que des considérations de religion, de nation, de race, de parti ou de classe sociale viennent s'interposer entre mon devoir et mon patient.

Je garderai le respect absolu de la vie humaine.

Même sous la menace, je n'admettrai pas de faire usage de mes connaissances médicales contre les lois de l'humanité.

Respectueux et reconnaissant envers mes Maîtres, je rendrai à leurs enfants l'instruction que j'ai reçue de leurs pères.

Que les hommes m'accordent leur estime si je suis fidèle à mes promesses.

Que je sois couvert d'opprobre et méprisé de mes confrères si j'y manque. 


\section{Analyse de la survie des patients avalanchés en arrêt cardiaque dans les Alpes du Nord.}

Introduction : Pathologie circonstancielle fréquente dans notre région, la prise en charge des avalanchés pose le problème du triage des patients victimes d'arrêt cardiaque (AC) réfractaire consécutivement à un ensevelissement complet. En effet, 3 mécanismes peuvent conduire à un $\mathrm{AC}$ dans ce contexte: l'anoxie, le traumatisme ou l'hypothermie. Seul l'AC par hypothermie sévère permet d'espérer une évolution neurologique favorable. En cas d'AC réfractaire, les critères actuels d'éligibilité à l'assistance circulatoire sont dictés par les recommandations internationales : absence d'un traumatisme sévère, température corporelle inférieure à $32^{\circ} \mathrm{C}$ et kaliémie inférieure à $10 \mathrm{mmol} / \mathrm{L}$.

Objectif: Mettre en évidence les facteurs associés à la survie afin d'optimiser le triage des patients avalanchés en AC réfractaire.

Matériel et méthodes : Cette étude rétrospective, observationnelle a été conduite de 1994 à 2013 dans les Alpes du Nord. Elle concerne tous les avalanchés en AC admis au déchocage suite à un ensevelissement par avalanche. Le registre du Réseau de Traumatologie Nord Alpin des Urgences a permis le recueil des données. Le triage pré-hospitalier suivait les recommandations internationales. A l'admission hospitalière, les patients transportés sous massage cardiaque étaient récusés à l'assistance circulatoire devant un traumatisme sévère diagnostiqué au bilan initial, une kaliémie supérieure à 10 $\mathrm{mmol} / \mathrm{L}$ ou une température centrale supérieure à $32^{\circ} \mathrm{C}$. Les facteurs associés à la survie hospitalière ont été déterminés par analyse univariée (test de Mann-Whitney). L'évolution neurologique était évaluée par le score Cerebral Performance Category (CPC) à 3 mois. Un score CPC de 1-2 représentant une évolution neurologique favorable.

Résultats : Quarante-huit patients (âge médian 33 ans, durée d'ensevelissement médiane 43 minutes, température corporelle médiane $28^{\circ} \mathrm{C}$ ) ont été inclus. Dix-huit patients présentaient une reprise d'activité circulatoire spontanée en pré-hospitalier. A l'admission hospitalière, 11 patients en AC réfractaire ont été récusés à l'assistance circulatoire du fait d'une hyperkaliémie ( $\mathrm{n}=8$ patients), d'une température supérieure à $32^{\circ} \mathrm{C}(\mathrm{n}=2$ patients) ou d'un traumatisme thoracique ( $\mathrm{n}=1$ patient). Vingt et un patients ont bénéficié d'une assistance circulatoire $(\mathrm{n}=19)$ ou pour une instabilité hémodynamique persistante $(n=2)$. Huit patients ont survécu et seulement 3 ont présenté une évolution neurologique favorable (CPC 1). Les facteurs pré-hospitaliers associés à la survie étaient la présence d'une poche à air lors de l'ensevelissement, de signes de vie avant l'AC (pas d'asystolie, mouvements respiratoires, et/ou score de Glasgow supérieur à 3 ) et l'existence d'un collapsus de recirculation (rescue collapse) défini par un $\mathrm{AC}$ à la mobilisation d'un patient en hypothermie profonde.

La kaliémie était plus élevée dans le groupe des non-survivants (5.6 [4.2-4.8] mmol/L) par rapport aux survivants $(3.2[2.7-4] \mathrm{mmol} / \mathrm{L}, \mathrm{P}=0.001)$. Les non-survivants présentaient davantage de troubles de coagulation que les survivants (Taux de Prothrombine: 64 [54-83] \% vs. 30 [19-51] \%, respectivement, $\mathrm{p}<0.01$ ). Parmi les 3 patients survivants sans séquelle neurologique, 2 ont présenté des durées d'ensevelissement exceptionnellement prolongées de 6 et 7 heures.

Conclusion: Le pronostic des patients victimes d'AC par avalanche est sombre puisque seulement 3 patients sur 48 ont présenté une évolution neurologique favorable. En pré-hospitalier, la présence d'une poche à air a été associée à la survie ainsi que la présence de signes de vie avant l'AC. La recherche des victimes doit être poursuivie malgré des durées prolongées d'ensevelissement. Avec l'hyperkaliémie, les troubles de coagulation pourraient intégrer l'algorithme de triage pour la mise en place d'une assistance circulatoire en cas d'AC réfractaire.

Mots Clés : avalanche, arrêt cardiaque, hypothermie, ensevelissement. 
